\title{
PRÁTICAS SUSTENTÁVEIS DE INOVAÇÃO PARA TOMADA DE DECISÃO BASEADA NA PERCEPÇÃO DE GESTORES E ASSOCIADOS: UM ESTUDO NAS ASSOCIAÇÕES ATLÉTICAS DO BANCO DO BRASIL
}

\author{
SUSTAINABLE PRACTICES OF INNOVATION FOR DECISION-MAKING BASED ON THE \\ PERCEPTION OF MANAGERS AND ASSOCIATES: A STUDY IN THE BANCO DO BRASIL ATHLETIC \\ ASSOCIATIONS
}

\author{
GERALDO LUIZ OLIVEIRA SILVA ${ }^{1}$ \\ ANETE ALBERTON ALBERTON ${ }^{2}$
}

Resumo: O presente estudo visa identificar e analisar as percepções de associados e dirigentes das Associações Atléticas Banco do Brasil (AABBs) no contexto nacional acerca da temática da sustentabilidade, na perspectiva de que contribuam para que os gestores possam tomar decisões estratégicas, estabelecendo um modelo de gestão. 0 método de pesquisa quantitativa, com abordagem descritiva, foi utilizado para analisar os questionários com perguntas semiestruturadas e fechadas aplicadas on line aos dirigentes e associados da amostra de 305 clubes no universo de 1.088 , selecionados pelo critério de previsibilidade, considerando aqueles que desenvolvem ou desenvolveram o Programa de Integração AABB Comunidade. Este programa tem como propósito fornecer assistência complementar à escola para crianças e adolescentes de 6 a 18 anos incompletos nas dependências dos clubes, em horários inversos ao escolar, que vivem em comunidades carentes. A amostra do estudo representa $28 \%$ do total de $A A B B s$, distribuídas em todas as regiões do Brasil e o estudo utilizou como base o conceito Triple Bottom Line. Os resultados apontaram que as práticas diárias e atividades coletivas dos clubes na dimensão ambiental são inexpressivas. $\mathrm{Na}$ dimensão social evidenciou-se a característica principal desses clubes como associações desportivas, de onde se percebe a integração esportiva como diferencial. Na análise econômica constatou-se a existência de credibilidade dos associados em relação às políticas financeiras internas, contudo, as poucas ações comunitárias apresentadas nas três dimensões, caracterizam esses clubes como entidades de pouca interação e participação da sociedade nos municípios onde estão inseridos.

Palavras-chave: Clube social. Sustentabilidade. Triple Bottom Line. Gestão sustentável.

Abstract: This study aims to identify and analyze the perceptions of members and leaders of Athletic Associations Bank of Brazil (AABBs) at the national level based on sustainability. The method of quantitative research with descriptive approach was used to analyze the questionnaires with semi-structured and closed questions applied online to the leaders and members of the sample of 305 clubs in the 1088 universe, selected by the predictability criterion considering those who develop or have developed the Program integration AABB Community that aims to provide additional assistance to school children and adolescents aged 6 to 18 years incomplete on the premises of the club, at times backward to school, living in poor communities. The sample represents $28 \%$ of total AABBs distributed in all

\footnotetext{
Data de submissão: 08/08/2017 Data de aceite: 17/06/2018 Data de publicação: 07/08/2018

1 PPGA - UNIVALI - BIGUAÇU - SC

2 PPGA - UNIVALI - BIGUAÇU - SC
} 
regions and the study used based on the concept of the Triple Bottom Line. The results showed that the daily practices and collective activities of the clubs in the environmental dimension are negligible. In the social dimension was evident the main feature of these clubs and sports associations, which is perceived sport integration as differential. In the economic analysis found the existence of credibility of the members in relation to internal financial policies, however, the few EU actions presented in three dimensions characterize these clubs as entities of little interaction and participation of society in the cities where they live.

Keywords: Social Club. Sustainability. Triple Bottom Line. sustainable management.

\section{INTRODUÇÃO}

Os clubes sociais existentes no país figuram entre as instituições mais tradicionais da sociedade brasileira formada por grupos de pessoas de diferentes áreas profissionais, mas que partilham interesses comuns voltados às atividades culturais, de lazer e desportivas (CBC, 2015). Libardi (2014) argumenta que os ingleses foram os precursores na criação dos clubes pelo mundo que, para manterem suas tradições culturais ao saírem de seu país em busca de terras longínquas entre os séculos XV e XVIII, formavam comunidades somente frequentadas por àqueles de suas origens.

Essa prática inspirou outras nações, que passaram a desenvolver hábitos semelhantes, dando consistência ao desenvolvimento de outros clubes. Segundo Camargo e Silva (2008) os clubes sociais começaram a se desenvolver no Brasil durante o século XVIII com influência dos povos europeus, destacando-se as comunidades de procedência germânica, tendo como objetivo o convívio social, cultural e a manutenção das tradições primitivas. Na concepção de Bramante (1999), Mezzadri (2000) e Capi e Marcellino (2009), os clubes representam uma confraria com objetivos definidos relacionados ao entretenimento e ao lazer voltado às populações capazes de se manifestarem nas diversas camadas sociais, por meio do associativismo.

Bramante (1999), Riede (2002) e Carvalho (2009) asseveram que, pelas características de organização associativa e seus conteúdos culturais, sociais, físicoesportivos, manuais, intelectuais, artísticos, filantrópicos e turísticos, essas instituições têm uma importância significativa na sociedade no processo de urbanização, contribuindo em larga escala para o desenvolvimento comunitário.

Porém, a institucionalização dos clubes como entidades sem fins lucrativos, segundo a Lei $n^{\circ} 9.790$, Cap. I, art. $1^{\circ}, \S 1^{\circ}$, não permite distribuição de eventuais excedentes operacionais a associados, conselheiros e diretores no exercício da função, impossibilitando que o gestor tenha a atuação diretiva como sua principal atividade profissional. Dessa forma, a administração é exercida voluntariamente por um associado disposto a colaborar com a instituição.

Os clubes sociais têm sido citados de forma secundária nos estudos acerca de temas como a prática e a atividade esportiva, o lazer e o entretenimento, a atividade profissional, deixando-se de mencionar questões problemáticas relacionadas à manutenção da estrutura física e à sua atuação social, econômica e ambiental (CARVALHO, 2009). Nas pesquisas de Capi e Marcellino (2009) e Mezzadri (2000), por exemplo, destacam-se a importância da 
formação profissional qualificada para a gestão dos clubes e a sistematização e o planejamento das práticas do esporte como componentes essenciais para sua evolução.

O objetivo deste artigo é analisar as percepções de associados e dirigentes das Associações Atléticas Banco do Brasil (AABBs) acerca da sustentabilidade, e identificar perspectivas que subsidiem os gestores na tomada de decisões estratégicas, estabelecendo um modelo de gestão que tenha como propósito a continuidade no atendimento e a contribuição às comunidades circunvizinhas, sob a luz da teoria dos três pilares - Triple Bottom Line (TBL).

Elkington (2012) assevera que sem a reestruturação para a sustentabilidade, uma vez que a competição será uma das maiores forças que irão direcionar o sistema Triple ambiental, econômico e social -, as organizações, independentemente da área de atuação, perderão a competitividade $\mathrm{e}$, consequentemente, o rumo para o desenvolvimento sustentável.

Analisar a atuação das AABBs nos aspectos relacionados à sustentabilidade com base no Triple Bottom Line (TBL) e identificar perspectivas que possam contribuir para uma melhor compreensão na forma de atuação desses clubes, servindo de modelo de gestão voltado à sustentabilidade no segmento, objetivando a sua continuidade no atendimento às gerações atuais e futuras, é o que se pretende atingir nesta pesquisa, contribuindo para a gestão sustentável nos clubes sociais e para a comunidade acadêmica.

\section{Contextualização do objeto de estudo - as AABBs}

Ao longo da sua existência, as AABBs tornaram-se um potencial econômico, social e cultural nas localidades onde estão inseridas, contribuindo com órgãos municipais, governamentais e entidades privadas na promoção de eventos, reuniões e atendimento a comunidades carentes. Entretanto, mudanças sistemáticas ocorridas nas últimas décadas têm exigido um repensar dos seus administradores, dos gestores do Banco do Brasil e daqueles que fazem parte do quadro de associados, acerca do que pode ser mais adequado aos clubes para a sua sustentabilidade.

Segundo Rech (2000), as AABBs, idealizadas para atender aos funcionários do BB e seus familiares, principalmente em localidades inóspitas - visto que, com frequência, a instituição precisava deslocar de seu lugar de origem funcionários recém-aprovados em concursos públicos -, evoluíram e tornaram-se referências nas cidades em que se instalaram, atendendo não somente os funcionários do $\mathrm{BB}$, mas também, uma representativa parcela da comunidade com o apoio de entidades municipais e privadas. As mudanças estruturais e tecnológicas ocorridas no BB, a partir da década de 1980, refletiram diretamente no desempenho e na proposta filosófica das AABBs.

\section{O Associativismo}

Historicamente, o associativismo se difundiu no Brasil por intermédio da Igreja no colonialismo, meados do século $\mathrm{XV}$, quando o país passava por um quadro organizacional caótico, motivado pelas fortes restrições de desenvolvimento das comunidades (CAPI; MARCELLINO, 2009). Fernandes e Castro (2005) afirmam que o associativismo se traduz em uma forma de organização da sociedade civil em que os cidadãos, por livre-arbítrio, agrupam-se para realizar atividades de interesse comuns sem objetivos econômicos. 
Pode-se afirmar que as entidades associativas contribuem para a redução de desigualdades sociais e para a efetivação dos direitos sociais, por meio de ações que buscam melhoria da qualidade de vida e aproveitamento das atividades públicas como vetor de desenvolvimento social (ARAÚJO; NASCIMENTO, 2012). Salamon (1998) salienta que há uma forte tendência em escala mundial à criação de organizações voluntárias, associativas e similares para prestar serviços sociais, buscar soluções locais nas comunidades, impedir a degradação ambiental, defender direitos civis e outras inúmeras ações que não são atendidas pelo Estado.

\section{O surgimento da denominação "Terceiro Setor" no Brasil}

Se o associativismo se difundiu no país em meados do século XV, a denominação "Terceiro Setor", segundo Falconer (1999), ocorreu na década de 1990, com a proposta de renovação do espaço público, resgate da solidariedade e da cidadania, humanização do capitalismo e de superação da pobreza, designando o conjunto de iniciativas provenientes da sociedade.

Na avaliação e caracterização do Terceiro Setor, Salamon (1998), Soares e Scarpin (2009) relatam que o surgimento e crescimento do Terceiro Setor decorrem de várias pressões e mudanças profundas e significativas no comportamento da sociedade, em suas demandas e necessidades, das instituições e até dos próprios governos, em decorrência de uma mudança de orientação política no Brasil, no que tange ao papel do Estado (Primeiro Setor), do Mercado (Segundo Setor) e, em especial, à forma de participação dos cidadãos na esfera pública. Traz na sua concepção um conjunto de mudanças sociais e tecnológicas, surgidas com a contínua crise de confiança da sociedade relacionada à capacidade de gerir do Estado. Assim, o Terceiro Setor se caracteriza pelas figuras jurídicas, sem fins lucrativos, representadas por fundações e associações geradoras de bens e serviços (SALAMON, 1998).

O Terceiro Setor se diferencia do Primeiro e do Segundo Setor em relação a vários aspectos estruturais e de operações, como a origem dos recursos, o perfil dos stakeholders e a forma de relacionamento interno e externo; por isso, exige papéis diferenciados e capacidades técnicas específicas (PEREIRA et al., 2013).

Salamon (1998) adverte que - mesmo a partir de um conjunto claro de mudanças sociais e tecnológicas, aliadas à contínua crise de confiança social na capacidade de gestão do Estado -, não há como o Terceiro Setor atuar de forma totalmente independente. Apesar de existirem outros termos para denominar as organizações do Terceiro Setor como instituto, entidade, organização de base comunitária, ONGs, centro de pesquisa, entre outros, juridicamente essas organizações são classificadas como associações ou fundações (ARAÚJO; CARRENHO, 2009).

De acordo com o Código Civil brasileiro (Lei $n^{\circ} 10.406 / 2002$ ) as fundações, tratadas nos arts. 62 a 69, somente podem ser instituídas por escritura pública ou testamento, e ter fins religiosos, morais, culturais ou de assistência sendo o controle e a fiscalização de responsabilidade do Ministério Público. Já as associações são definidas nos arts. 53 a 61 como entidades formadas pela união de pessoas para fins não econômicos, não existindo direitos e obrigações recíprocos entre seus associados que possuem direitos iguais e somente podem ser excluídos por justa causa em procedimento que lhes assegure direito de defesa e de recurso, nos termos previstos no estatuto.

\section{A gestão do lazer}


Integrantes do Terceiro Setor, as associações sócio recreativas fazem parte de um cenário social complexo e vêm sofrendo transformações significativas ao longo do tempo, provocadas por aspectos políticos, sociais, econômicos e culturais (SILVA, 2007; CAMARGO; SILVA, 2008). A capacidade transformadora do ser humano de adaptar-se permanentemente às mudanças nos aspectos citados por Silva (2007) e Camargo e Silva (2008), em uma sociedade em permanente processo de evolução, representa um grande desafio na gestão do lazer e da recreação dessas associações.

Segundo Bramante (1999), o lazer passou a ocupar espaço de relevância no cenário acadêmico internacional a partir da década de 1950, tornando-se um amplo campo de estudos e pesquisas em diversos enfoques profissionais como a administração, filosofia, história, antropologia, sociologia, psicologia, geografia, entre outras. Bramante (1999) argumenta ainda, que o seu caráter interdisciplinar tem sido uma tônica na busca de sua compreensão.

No Brasil, observa-se um crescimento na visibilidade do lazer enquanto tema de estudos, devido aos significativos espaços ocupados nos jornais, nos periódicos de informação geral e no mundo acadêmico, destacando a organização de grupos de pesquisa advindo das mais diversas áreas de conhecimento (GOMES; MELO, 2003).

Gomes et al. (2010) argumentam, entretanto, que faltam pesquisas que permitam conhecer a realidade do lazer de forma mais consistente e que as vivências de lazer não devem ser tratadas somente como meros recursos metodológicos, mas como importantes manifestações culturais que representem singularidades em cada contexto. Mas, como pode ser caracterizado o "lazer"? O comportamento do ser humano e o prazer em gozar de momentos de descontração são peculiares e definidos individualmente.

No entendimento de Chaves et al. (2003), o lazer é a cultura compreendida no seu sentido mais amplo, que é praticada, fruída ou conhecida no tempo disponível das pessoas, que propicia determinadas condições que estão ligadas ao descanso, divertimento e desenvolvimento. Para Silva (2007) a percepção do lazer é uma condição auferida na busca pelo prazer e encontra-se, muitas vezes, carregada de valores atribuídos pelas pessoas, favorecida pelos interesses simbólicos construídos na sociedade. Bramante (1999) afirma que o lazer se traduz por uma dimensão privilegiada da expressão de uma experiência pessoal criativa, de prazer e que não se repete no tempo/espaço, cujo eixo principal é a ludicidade.

Embora a percepção do lazer pelos mais variados autores e mesmo pelas pessoas da sociedade em geral possa ter características semelhantes e relação com a ociosidade, Gomes et al. (2010) argumentam que o lazer não deve ser pensado apenas como algo que existe para renovar as energias para o trabalho, mas sim visto em sua essência, como um fenômeno sociocultural que diz respeito a práticas culturais diversas, as quais são coletivamente produzidas em cada realidade histórico-social.

Diante dessa diversificação de definições, a gestão eficiente e eficaz do lazer e recreação nas instituições associativas manifesta-se como uma importante ferramenta a ser explorada na gestão da sustentabilidade.

\section{Gestão Sustentável}

Nos últimos 200 anos, o problema ambiental tem se agravado com a intensificação da industrialização, a intervenção do homem sobre a natureza, provocando o aquecimento 
global, o desequilíbrio nos ecossistemas e a ameaça às reservas de água (DIAS, 2011; NETO, 2011; PEREIRA et al., 2012).

Mesmo não sendo recente, somente nas últimas décadas do século $X X$ a discussão sobre desenvolvimento sustentável passou a ser debatida de forma mais contundente. Breier, Jung e Ten Caten (2011), Hogevold e Svensson (2012) e Almeida (2001) asseveram que o termo desenvolvimento sustentável difundiu-se em decorrência da reunião da Comissão Mundial sobre Meio Ambiente e Desenvolvimento, no ano de 1987, por meio do relatório Brundtland, no documento denominado "nosso Futuro Comum" que propôs a utilização das riquezas naturais sem comprometer a capacidade das gerações futuras satisfazerem suas próprias necessidades.

O Quadro 1 apresenta aspectos consolidados na visão cartesiana/mecanicista comparados à visão sustentável.

Quadro 1 - Aspectos comparativos entre os paradigmas

\begin{tabular}{|l|l|}
\hline \multicolumn{1}{|c|}{ Cartesiano / Mecanicista } & \multicolumn{1}{c|}{ Sustentável } \\
\hline - Reducionista, mecanicista, tecnocêntrico & - Orgânico, holístico, participativo \\
\hline - Fatos e valores não relacionados & - Fatos e valores fortemente relacionados \\
\hline $\begin{array}{l}\text { - Preceitos éticos desconectados das práticas } \\
\text { cotidianas }\end{array}$ & - Ética integrada ao cotidiano \\
\hline - Separação entre o objetivo e o subjetivo & - Interação entre o objetivo e o subjetivo \\
\hline $\begin{array}{l}\text { - Seres humanos e ecossistemas separados, em } \\
\text { uma relação de dominação }\end{array}$ & $\begin{array}{l}\text { - Seres humanos inseparáveis dos ecossistemas, em } \\
\text { uma relação de sinergia }\end{array}$ \\
\hline - Conhecimento compartimentado e empírico & - Conhecimento indivisível, empírico e intuitivo \\
\hline - Relação linear de causa e efeito & - Relação não linear de causa e efeito \\
\hline - Natureza entendida como descontínua, o todo & - Natureza entendida como conjunto de sistemas \\
formado pela soma das partes & $\begin{array}{l}\text { interrelacionados. O todo maior que a soma das } \\
\text { partes }\end{array}$ \\
\hline - Bem-estar avaliado por relação de poder & $\begin{array}{l}\text { - Bem-estar avaliado pela qualidade das inter- } \\
\text { (dinheiro, influência, recursos) }\end{array}$ \\
\hline - Ênfase na quantidade (renda per capita) & - Ênfase na qualidade (qualidade de vida) \\
\hline - Análise & - Síntese \\
\hline - Centralização de poder & - Descentralização de poder \\
\hline - Especialização & - Transdisciplinaridade \\
\hline - Ênfase na competição & - Ênfase na cooperação \\
\hline - Pouco ou nenhum limite tecnológico & - Limite tecnológico definido pela sustentabilidade \\
\hline
\end{tabular}
Fonte: Almeida (2001).

A diferenciação entre a visão cartesiana/mecanicista e a visão sustentável apresentada no Quadro 1 demonstra a interação dos aspectos sustentáveis no qual as dimensões ambiental, social e econômica se relacionam continuamente e os aspectos cartesiano/mecanicista em que as dimensões são tratadas separadamente. Essas transições do tradicional para o sustentável são elementares para que a sustentabilidade seja tratada como um conjunto de práticas que tenham como ponto principal uma atuação globalizada e integrada.

Flores (2014) relata que o desenvolvimento sustentável e sustentabilidade, responsabilidade social, meio ambiente, transparência, fazem parte de um todo, e que a maneira para se alcançar a sustentabilidade passa, necessariamente, pelo desenvolvimento sustentável, sendo possível verificá-lo se as pessoas, organizações e instituições estiverem envolvidas por um objetivo que direcione seus comportamentos para a sustentabilidade. 
Diante dessas afirmativas, o que emerge é a demanda por sinais que possam orientar a sociedade sobre os caminhos a serem trilhados em termos de políticas sociais, padrões de consumo e produção, e a mudança de perspectiva que se reflete na tomada de decisão intrínseca ao comportamento sustentável (PHILIPPI et al, 2012).

\section{Sustentabilidade}

Até a década de 1960, as organizações preocupavam-se apenas com a eficiência dos sistemas produtivos, predominando na administração a noção de mercados e recursos ilimitados. Essa prática revelou-se equivocada a partir do crescimento da consciência ecológica na sociedade, no governo e nas próprias empresas que passaram a incorporar essa orientação em suas estratégias (DONAIRE, 2010).

No entendimento de Freeman, Martin e Parmar (2007), nos últimos 200 anos uma grande quantidade de inovações nos costumes e no mercado global transformou a vida de milhões de pessoas, porém, as consequências danosas oriundas da degradação ambiental, da desigualdade social e do poder econômico distribuído de forma desigual têm causado prejuízos incalculáveis às sociedades.

O principal desafio para as organizações que buscam ser mais sustentáveis é identificar uma forma adequada de gestão das dimensões ambiental e social, integrando-as aos benefícios econômico-financeiros (JABBOUR; JABBOUR, 2013). Segundo Hart e Milstein (2003), a gestão sustentável de uma empresa contribui com o desenvolvimento sustentável, gerando, simultaneamente, benefícios econômicos, sociais e ambientais - conhecidos como os três pilares da sustentabilidade.

Considerando o desenvolvimento sustentável nesses três pilares dentro das organizações, Dias (2011) as define da seguinte forma:

a) economicamente: empresas que são economicamente viáveis e que deem retorno ao investimento realizado;

b) socialmente: empresas que proporcionam condições de trabalho adequadas aos empregados, contemplem a diversidade cultural e ensejem aos deficientes de modo geral, oportunidade de vínculo empregatício;

c) ambientalmente: empresas que se pautam pela eco eficiência dos processos produtivos, adotam a produção mais limpa e oferecem condições de desenvolvimento de uma cultura ambiental organizacional e adotam uma postura de responsabilidade ambiental.

Werbach (2010) descreve que pôr em prática uma gestão voltada para a sustentabilidade é indispensável para a sobrevivência das empresas em um mundo no qual as mudanças são cada vez mais céleres e as dimensões social, econômica, cultural e ambiental não podem ser desprezadas com o argumento empresarial focado simplesmente em aumentar receitas ou cortar custos para inflar o lucro final.

Jabbour e Jabbour (2013) sustentam que, ainda que alguns dirigentes organizacionais insistam em desconsiderar os aspectos socioambientais durante a prática administrativa, a inclusão das preocupações socioambientais no dia a dia das organizações de classe-mundial é um processo irreversível. Muito além desse consenso sobre sustentabilidade, há um desacordo entre executivos quanto ao significado e a motivação. Para alguns, é um mandato moral; para outros, uma exigência legal. Para alguns outros, a sustentabilidade é percebida como um custo inerente ao fato de se fazer negócios (HART, MILSTEIN, 2003). Fato é que ainda são poucas as empresas que tratam a sustentabilidade 
como uma oportunidade de negócios, que poderá diminuir seus custos e elevar seus rendimentos e sua participação de mercado.

Munck (2013) assevera que mesmo quando se busca abordagens, modelos e ferramentas para a implantação de uma gestão de sustentabilidade, o que mais se destaca é a adoção e aplicação de ferramentas próximas dos sistemas de gestão ambiental, porém, afirma que a Sustentabilidade Organizacional (SO) vai além desses modelos. Em sua análise, a ênfase nesse processo está nas pessoas, defendendo que o agir coletivo e o agir individual são os alicerces da organização em busca da gestão sustentável.

\section{Responsabilidade social - ferramenta para a sustentabilidade organizacional}

As ponderações, preocupações e análises relacionadas à responsabilidade social nas empresas estão em processo progressivo neste século XXI, contudo, as discussões envolvendo esse tema já são abordadas há mais de 100 anos (SILVA, 2006).

Segundo Ashley (1999), no ano de 1916, Henry Ford, presidente e acionista majoritário da empresa americana Ford Motor Company, considerado como um dos pioneiros da responsabilidade social corporativa, decidiu não distribuir parte dos dividendos a um grupo de acionistas da Ford, entre eles os irmãos, John e Horace Dodge, revertendo para investimentos na capacidade de produção, aumento de salários dos empregados e na criação de fundo de reservas para possível redução de receitas devido ao corte nos preços dos carros, argumentando a realização de objetivos sociais. Os irmãos Dodge não concordaram com a decisão e levaram o caso para a Suprema Corte de Michigan (EUA), a qual se posicionou a favor dos reclamantes, justificando que uma empresa comercial não poderia mudar o seu foco na lucratividade totalmente em prol dos seus acionistas.

Até meados do século XX a equação lucro versus função social não fazia parte da estratégia das empresas. Ética empresarial e responsabilidade social corporativa vêm ganhando importância com o crescente aumento da complexidade dos negócios que exige uma nova maneira de pensar e agir e as disparidades sociais que levam os empresários a direcionar o desenvolvimento sustentável de forma integrada nos aspectos econômico, social e ambiental (ASHLEY, 2002).

\section{Teoria dos três pilares - Triple Bottom Line - (TBL)}

O modelo preconiza que para uma organização ser sustentável deve ser financeiramente viável, socialmente justa e ambientalmente responsável. Segundo Oliveira et al. (2012), Melo (2013) e Boff (2013) o conceito surgiu no ano de 1994 na pesquisa feita pelo sociólogo John Elkington, conhecido também pela expressão -3P (people, planet e profit) e PPL (pessoa, planeta e lucro) que orienta a expansão do modelo tradicional de negócios focado em resultados financeiros para um novo modelo, que inclui a performance ambiental e social atendendo às gerações atuais sem comprometer as gerações futuras.

Elkington (2012) argumenta que aqueles que defendem e trabalham focados na linha dos três pilares precisam se tornar formadores de opinião e de mercado, trazendo tecnologias e abordagens sustentáveis que até então estiveram na periferia do mundo moderno para dentro das práticas atuais, independentemente do tamanho da organização e do ramo em que atua.

\section{Indicadores de sustentabilidade}


Embora o conjunto dos modelos de indicadores de sustentabilidade procure contemplar todas as variáveis que uma organização, entidade ou sociedade civil pode utilizar para determinar o nível de envolvimento ao qual cada uma esteja comprometida com a questão, não existe nenhum modelo que contemple todas as variáveis a serem aplicadas em um sistema de sustentabilidade (VELEVA; ELLENBECKER, 2000).

Com base nos estudos de Louette (2009), Van Bellen (2006), Bardall, Alberton e Campos (2010), Hardi e Zdan (1997), Nascimento, Tello e Oliveira (2005) e Prescott-Allen (2001), foram pesquisados 14 modelos ou sistemas de indicadores de sustentabilidade empregados com diferentes abordagens, os quais atuam com foco nas questões, econômica, social e ambiental. O Quadro 1 apresenta, simplificadamente, as características de cada um.

\section{Quadro 1 - Modelos de mensuração da sustentabilidade}

\begin{tabular}{|c|c|c|c|}
\hline \multicolumn{3}{|c|}{ Modelo } & Característica geral \\
\hline 1 & $\begin{array}{l}\text { Princípios de } \\
\text { Bellagio }\end{array}$ & & $\begin{array}{l}\text { pios que orientam a avaliação do progresso rumo ao desenvolvimento } \\
\text { ttável. Podem ser aplicados de forma conjunta em comunidades locais e } \\
\text { esas ou em organismos internacionais (HARDI; ZDAN, 1997). }\end{array}$ \\
\hline 2 & \multicolumn{2}{|l|}{$\begin{array}{l}\text { Ecological Footprint } \\
\text { Method }\end{array}$} & $\begin{array}{l}\text { Utilizado por cientistas, empresas, governos, agências, indivíduos e } \\
\text { instituições para monitorar o uso de recursos ecológicos e promover o } \\
\text { desenvolvimento sustentável, (LOUETTE, 2009). }\end{array}$ \\
\hline 3 & DNA B & \multicolumn{2}{|r|}{$\begin{array}{l}\text { Compara a realidade brasileira com expectativas de futuro e a situação de outros } \\
\text { países analisando a mobilização dos setores públicos e privados envolvidos em } \\
\text { projetos de desenvolvimento (LOUETTE, 2009). }\end{array}$} \\
\hline 4 & \multicolumn{2}{|c|}{$\begin{array}{l}\text { Environmental } \\
\text { Performance Index }\end{array}$} & $\begin{array}{l}\text { Concebido com a proposta de quantificar e classificar numericamente o } \\
\text { desempenho ambiental de organizações e países (LOUETTE, 2009). }\end{array}$ \\
\hline 5 & $\begin{array}{l}\text { Compass of } \\
\text { Sustainability }\end{array}$ & \multicolumn{2}{|r|}{$\begin{array}{l}\text { Oferece um quadro abrangente e intuitivo para a gestão da sustentabilidade } \\
\text { agrupando os indicadores em quatro quadrantes com base na metáfora da bússola, } \\
\text { sendo: natureza, economia, sociedade e bem-estar (ATKISSON; HATCHER, 2014). }\end{array}$} \\
\hline 6 & \multicolumn{2}{|c|}{$\begin{array}{l}\text { Dow Jones } \\
\text { Sustainability Index - } \\
\text { DJSI }\end{array}$} & $\begin{array}{l}\text { Índice global criado para acompanhar o desempenho financeiro das empresas } \\
\text { orientadas para a sustentabilidade em todo o mundo com base na análise de } \\
\text { materiais financeiros, econômicos, ambientais e sociais (DOW JONES, 2015). }\end{array}$ \\
\hline 7 & & \multicolumn{2}{|r|}{$\begin{array}{l}\text { Agregação de indicadores pertencentes às dimensões: econômica, social e } \\
\text { ambiental, incluindo a institucional para que o modelo possa ser utilizado com } \\
\text { credibilidade na tomada de decisão junto aos envolvidos com a gestão (CAMPOS e } \\
\text { RIBEIRO, 2007). }\end{array}$} \\
\hline 8 & \multicolumn{2}{|c|}{$\begin{array}{l}\text { IDS -Indicadores de } \\
\text { Desenvolvimento } \\
\text { Sustentável }\end{array}$} & $\begin{array}{l}\text { Disponibiliza um sistema de informações para o acompanhamento da } \\
\text { sustentabilidade do padrão de desenvolvimento do país. Integra as dimensões } \\
\text { social, ambiental, econômica e institucional (LOUETTE, 2009). }\end{array}$ \\
\hline 9 & & \multicolumn{2}{|r|}{$\begin{array}{l}\text { Utilizado para avaliar e relatar o progresso relacionado com as sociedades } \\
\text { sustentáveis associando, indicadores sociais e ambientais, avaliando as pessoas e o } \\
\text { meio ambiente por meio de uma escala de índices (LOUETTE, 2009; VAN BELLEN, } \\
\text { 2006). }\end{array}$} \\
\hline 10 & \multicolumn{2}{|l|}{$\begin{array}{l}\text { Responsible } \\
\text { Competitiveness } \\
\text { Index }\end{array}$} & $\begin{array}{l}\text { Tem como propósito demonstrar como e quais os países estão atingindo } \\
\text { crescimento econômico sustentável com base em práticas de } \\
\text { responsabilidade social (NASCIMENTO; TELLO; OLIVEIRA, 2005). }\end{array}$ \\
\hline 11 & Instituto & \multicolumn{2}{|r|}{$\begin{array}{l}\text { Seus indicadores contribuem para melhor análise e complementariedade do } \\
\text { balanço social das empresas em razão da associação entre seus indicadores e o } \\
\text { Modelo de Balanço Social do Instituto Brasileiro de Análises Sociais e Econômicas } \\
\text { (IBASE). }\end{array}$} \\
\hline 12 & \multicolumn{2}{|l|}{$\begin{array}{l}\text { The Well-being of } \\
\text { Nations - WN }\end{array}$} & $\begin{array}{l}\text { Utilizado para que a sociedade meça e conheça as condições das pessoas por } \\
\text { meio do índice de bem-estar humano, dos ecossistemas, bem-estar integrado } \\
\text { (humano/ecossistema) e relacionado ao estresse (PRESCOTT-ALLEN, 2001). }\end{array}$ \\
\hline 13 & $\begin{array}{l}\text { Global } \\
\text { Reporting }\end{array}$ & & $\begin{array}{l}\text { rado para demonstrar o desempenho econômico, social e ambiental de uma } \\
\text { ização. Concebido para organizações, independentemente do seu porte, setor }\end{array}$ \\
\hline
\end{tabular}




\begin{tabular}{|c|l|l|l|}
\hline 14 & Initiative - GRI & \multicolumn{2}{l|}{ ou localidade (GRI, 2014). } \\
\hline Method & $\begin{array}{l}\text { Social Footprint } \\
\text { Messoas e na sociedade em larga escala. (LOUETTE, 2009). }\end{array}$ \\
\hline
\end{tabular}

Fonte: Elaborado pelo autor

De acordo com Ranganathan (1998), Breier, Jung e Ten Caten (2011), Depontil e Almeida (2001), Van Bellen (2006), Neto (2006), Bardall (2008), Barros e Silva (2012) e Louette (2009), os indicadores de sustentabilidade são ferramentas essenciais no processo de medição e aferição, indispensáveis para conhecimento e análise das características e particularidades de diferentes sistemas, possibilitando; desse modo, a inserção de atitudes e tomada de decisão sustentáveis. Malheiros et al (2008) asseveram que a dificuldade de se estabelecer um modelo de avaliação que atenda todos os parâmetros está relacionado ao fato de que o desenvolvimento humano e a mudança ambiental estão interligados de tal forma que não podem ser tratados como um processo individualizado.

Com base no estudo realizado por Barddal (2008), foram analisadas as seguintes características para a definição dos modelos a serem utilizados: dimensão da sustentabilidade, preponderância de dimensão, esfera de aplicação, público de interesse, finalidade do método, tipologia dos dados, uso de índices/ indicadores, complexidade, dependência e participação, ou seja, o tipo de abordagem. Os modelos Global Report Initiative, Instituto Ethos e Dashboard of Sustainability, apresentaram maior aderência diante das características apresentadas, conforme demonstrado no Quadro 2.

\section{Quadro 2- Comparativo dos modelos selecionados}

\begin{tabular}{|c|c|c|c|}
\hline & $\begin{array}{l}\text { Global Reporting } \\
\text { Initiative }\end{array}$ & Instituto Ethos & $\begin{array}{l}\text { Dashboard of } \\
\text { Sustainability }\end{array}$ \\
\hline $\begin{array}{l}\text { Dimensões de } \\
\text { sustentabilidade }\end{array}$ & $\begin{array}{l}\text { Econômica } \\
\text { Ambiental } \\
\text { Social }\end{array}$ & Social & $\begin{array}{l}\text { Econômica } \\
\text { Ambiental } \\
\text { Social - Institucional }\end{array}$ \\
\hline $\begin{array}{l}\text { Preponderância } \\
\text { de dimensão }\end{array}$ & Não há & Social & Não há \\
\hline $\begin{array}{l}\text { Esfera de } \\
\text { aplicação }\end{array}$ & Organizacional & Organizacional & $\begin{array}{l}\text { Continental } \\
\text { Regional - Local } \\
\text { Organizacional }\end{array}$ \\
\hline $\begin{array}{l}\text { Público de } \\
\text { interesse }\end{array}$ & Stakeholders & Stakeholders & $\begin{array}{l}\text { Dirigentes públicos ou } \\
\text { privados }\end{array}$ \\
\hline $\begin{array}{l}\text { Finalidade do } \\
\text { método }\end{array}$ & $\begin{array}{l}\text { Elaborar diretrizes de } \\
\text { sustentabilidade. } \\
\text { Comunicar os impactos e } \\
\text { resultados econômicos, } \\
\text { sociais e ambientais } \\
\text { decorrentes das } \\
\text { atividades empresariais. }\end{array}$ & $\begin{array}{l}\text { Ajudar as empresas a } \\
\text { gerir os impactos } \\
\text { sociais e ambientais }\end{array}$ & $\begin{array}{l}\text { Medir a utilização de } \\
\text { estoques e fluxos das } \\
\text { dimensões que compõem o } \\
\text { desenvolvimento } \\
\text { sustentável. }\end{array}$ \\
\hline Tipologia dos dados & $\begin{array}{l}\text { Quantitativos } \\
\text { Qualitativos }\end{array}$ & $\begin{array}{l}\text { Quantitativos } \\
\text { Qualitativos }\end{array}$ & $\begin{array}{l}\text { Quantitativos com dimensão } \\
\text { qualitativa }\end{array}$ \\
\hline $\begin{array}{l}\text { Uso de índices e ou/ } \\
\text { indicadores }\end{array}$ & $\begin{array}{l}\text { Trabalha com indicadores } \\
\text { e produz relatórios }\end{array}$ & $\begin{array}{l}\text { Trabalha com } \\
\text { indicadores e gera } \\
\text { notas }\end{array}$ & $\begin{array}{l}\text { Trabalha com indicadores e } \\
\text { com índices }\end{array}$ \\
\hline Complexidade & Mediana complexidade & Mediana complexidade & Mediana complexidade \\
\hline Dependência & Baixa & Baixa & Alta/média \\
\hline Participação & Abordagem mista & Abordagem mista & Abordagem mista \\
\hline
\end{tabular}

Fonte: Adaptado de Barddal (2008). 
Ranganathan (1998) considera que, para atender às expectativas sustentáveis de uma organização, os indicadores devem estar alinhados a necessidades variadas, considerando três características de mensuração básicas: comparabilidade, que torna possível acompanhar o desempenho entre empresas; completude, quanto à aplicação entre as empresas; e confiabilidade, para que outras organizações confiem nos indicadores e possam tomar decisões com base nos resultados obtidos.

Além desses aspectos desenvolvidos apresentados no Quadro 2, o autor afirma que esses modelos reúnem um conjunto de indicadores de fácil interpretação, apresentam clareza nos seus propósitos e aplicabilidade em organizações públicas e privadas de qualquer segmento. São modelos que possuem bases de dados relacionadas com a entidade pesquisada e desfrutam de reconhecimento no contexto nacional e internacional, já tendo sido utilizados por organizações de pequeno, médio e grande porte. Os modelos selecionados, fundamentados no Triple Bottom Line, norteiam o estudo, no que se refere às análises das práticas sustentáveis nos clubes sociais.

\section{Procedimentos Metodológicos}

Collis e Hussey (2005) sugerem que a metodologia deve direcionar os estudos com base em seis questões principais: porque coletar, o que coletar, de onde coletar, quando coletar, como coletar, como analisar o conjunto de dados coletados. Esta pesquisa, então, apoia-se nos relatórios das AABBs denominado como "Projeto Diagnóstico das AABBs 2013" e nas respostas dos dirigentes e associados, com base em questionários fechados por meio da ferramenta Surveymonkey, a fim de compor os dados para que possam ser analisados e, assim, demonstrar como se apresentam as percepções dos participantes da pesquisa acerca das ações das $A A B B s$ em relação à sustentabilidade.

As $A A B B s$ são segmentadas, segundo critérios da FENABB, em quatro categorias: pequena - até 200 associados; média - até 500 associados; grande - até 1000 associados; e especial - acima de 1000 associados. Esta pesquisa se concentra em 305 AABBs que desenvolvem ou desenvolveram o Programa Integração AABB Comunidade, em parceria com entidades locais que atuam com foco no desenvolvimento social, selecionadas pelo critério de previsibilidade com base nas seguintes razões: representam $28 \%$ do total de AABBs ativas no país; estão presentes em todas as regiões; possuem estrutura administrativa adequada; e por entender que a implantação de um programa de integração com a comunidade em um clube social representa um viés diferenciado na busca da sustentabilidade.

Mesmo utilizando o critério de previsibilidade dentro da população, a amostra foi realizada de forma aleatória no universo das $A A B B s$ participantes do Programa AABB Comunidade e no total de clubes, de acordo com cada segmento, no período de setembro de 2015 a fevereiro de 2016.

A estratificação regional das associações pesquisadas considerou a amostra mínima de $95 \%$ de probabilidade, com um erro amostral máximo de 5\%. Para a obtenção do tamanho da amostra foram utilizadas as fórmulas [1] e [2] (BARBETTA, 2006)

$$
\begin{gathered}
n_{0}=1 / E^{2}{ }_{0}[1] \\
n=N \cdot n_{0} / N+n_{0}[2]
\end{gathered}
$$

Onde:

$\mathrm{N}$ representa o tamanho (número de elementos) da população;

$\mathrm{n}$ representa o tamanho (número de elementos) da amostra; 
$\mathrm{n}_{\mathrm{o}}$ representa a primeira aproximação para o tamanho da amostra;

$\mathrm{E}_{\mathrm{o}}$ representa o erro amostral tolerável.

Considerando a população de AABBs do Programa Integração AABB Comunidade (305) e o número de associados nesses clubes (92.047), a inserção dos dados na fórmula apresentada resultou na amostra mínima de 173 dirigentes de AABBs e 398 associados. A amostra final, porém, totalizou 222 respondentes entre os dirigentes e 505 associados distribuídos nas cinco regiões.

Percebe-se, na distribuição regionalizada, uma distribuição proporcional nas regiões com destaque para a região Sul que apresenta os números mais expressivos entre dirigentes e associados conforme demonstra a Tabela 1.

Tabela 1 - Distribuição dos associados e AABBs pesquisadas por região.

\begin{tabular}{|c|c|c|c|c|c|c|c|c|}
\hline $\begin{array}{l}\text { Regiões/ } \\
\text { AABBs }\end{array}$ & População & $(\%)$ & $\begin{array}{c}\text { Amostra } \\
\text { Final }\end{array}$ & (\%) & Associados & (\%) & $\begin{array}{c}\text { Amostra } \\
\text { Final }\end{array}$ & (\%) \\
\hline Norte & 19 & 6,23 & 17 & 7,6 & 7.315 & 8 & 31 & 6,1 \\
\hline Pequenas & 5 & 1,64 & & & 705 & 0,77 & & \\
\hline Médias & 9 & 2,95 & & & 2.690 & 2,94 & & \\
\hline Grandes & 3 & 0,98 & & & 1.900 & 2,09 & & \\
\hline Especiais & 2 & 0,66 & & & 2.020 & 2,20 & & \\
\hline Nordeste & 139 & 45,57 & 82 & 37,0 & 40.040 & 43 & 123 & 24,4 \\
\hline Pequenas & 82 & 26,89 & & & 10.560 & 11,00 & & \\
\hline Médias & 40 & 13,11 & & & 11.200 & 12,00 & & \\
\hline Grandes & 12 & 3,93 & & & 7.040 & 7,50 & & \\
\hline Especiais & 5 & 1,64 & & & 11.240 & 12,50 & & \\
\hline Centro Oeste & 27 & 8,85 & 19 & $8,5 \%$ & 12.955 & 14 & 48 & 9,5 \\
\hline Pequenas & 12 & 3,93 & & & 1.775 & 1,93 & & \\
\hline Médias & 8 & 2,62 & & & 2.010 & 2,00 & & \\
\hline Grandes & 5 & 1,64 & & & 2.870 & 3,00 & & \\
\hline Especiais & 2 & 0,66 & & & 6.300 & 7,07 & & \\
\hline Sudeste & 55 & 18,04 & 43 & 19,4 & 13.782 & 15 & 39 & 7,7 \\
\hline Pequenas & 34 & 11,15 & & & 4.262 & 4,63 & & \\
\hline Médias & 15 & 4,93 & & & 4.260 & 4,63 & & \\
\hline Grandes & 3 & 0,98 & & & 2.710 & 2,94 & & \\
\hline Especiais & 3 & 0,98 & & & 2.550 & 2,80 & & \\
\hline Sul & 65 & 21,31 & 61 & 27,5 & 17.955 & 20 & 264 & 52,3 \\
\hline Pequenas & 38 & 12,46 & & & 4.450 & 4,90 & & \\
\hline Médias & 18 & 5,90 & & & 4.985 & 5,50 & & \\
\hline Grandes & 6 & 1,97 & & & 3.620 & 4,10 & & \\
\hline Especiais & 3 & 0,98 & & & 4.900 & 5,50 & & \\
\hline Total Geral & 305 & 100 & 222 & 100 & 92.047 & 100 & 505 & 100 \\
\hline
\end{tabular}

Fonte: Elaborada pelo autor

Freitas et al. (2000) e Hair et al. (2005) entendem que no estudo exploratório é recomendável que o pesquisador colete os dados por meio da pesquisa survey, elabore questionários focados em tópicos específicos e em entrevistas pessoais. Os questionários respondidos foram armazenados em banco de dados e para análise dos resultados, as respostas apresentadas por meio de números de 1 (insatisfeito) a 5 (muito satisfeito).

O Quadro 3 apresenta os indicadores utilizados pelos modelos selecionados (GRI, SD e Instituto Ethos) correlacionados com os indicadores das AABBs na dimensão econômica 
de acordo com o "Projeto Diagnóstico das AABBs - 2013" utilizado pela FENABB para análise dos clubes.

Quadro 3 - Integração dos indicadores na dimensão econômica

\begin{tabular}{|c|l|l|}
\hline Modelo & \multicolumn{1}{|c|}{$\begin{array}{c}\text { Indicadores } \\
\text { Dimensão Econômica }\end{array}$} & \multicolumn{1}{c|}{ Indicadores das AABBs } \\
\hline ETHOS & Gestão participativa & $\begin{array}{l}\text { - Participação dos associados no sistema de gestão, na definição e } \\
\text { no aperfeiçoamento dos serviços oferecidos pelo clube. }\end{array}$ \\
\hline ETHOS & Governança da organização & - Performance da Governança da AABB (atuação dos diretores) \\
\hline GRI/SD & Estado financeiro & - Investimento na infraestrutura \\
\hline \multirow{2}{*}{ SD/GRI } & \multirow{2}{*}{ Performance econômica } & - Compatibilidade da mensalidade com os serviços oferecidos. \\
\cline { 3 - 4 } & & $\begin{array}{l}\text { - Compatibilidade da mensalidade com relação aos clubes da região } \\
\text { - Valor cobrado dos associados em eventos, apresentações, etc., } \\
\text { (fora a mensalidade) é adequado e justo. }\end{array}$ \\
\hline
\end{tabular}

Fonte: Elaborado pelo autor.

Conforme ilustra o Quadro 3, são apresentados seis indicadores na dimensão econômica das AABBs, relacionados a quatro indicadores dos modelos utilizados para análise da sustentabilidade nos clubes. O Quadro 4 apresenta a relação entre os indicadores dos modelos selecionados com os indicadores das AABBs na dimensão social.

Quadro 4 - Correlação dos indicadores da dimensão social

\begin{tabular}{|c|c|c|}
\hline Modelo & Indicadores - Dimensão Social & Indicadores das AABBs \\
\hline ETHOS & Relacionamento com os consumidores & - Atendimento aos associados \\
\hline \multirow{3}{*}{ ETHOS } & \multirow{3}{*}{$\begin{array}{l}\text { Compromisso com o desenvolvimento } \\
\text { comunitário / com a gestão social }\end{array}$} & - Desenvolvimento de atividades sociais \\
\hline & & - Desenvolvimento de atividades esportivas \\
\hline & & - Desenvolvimento de atividades culturais \\
\hline ETHOS & $\begin{array}{l}\text { Estratégia de comunicação responsável } \\
\text { e educação para o consumo consciente }\end{array}$ & $\begin{array}{l}\text { - Estratégia de comunicação com os associados } \\
\text { - Promoção de campanhas, projetos e programas } \\
\text { educativos voltados para os associados e a comunidade }\end{array}$ \\
\hline $\begin{array}{l}\text { ETHOS } \\
\text { GRI }\end{array}$ & $\begin{array}{l}\text { Comunidades locais } \\
\text { Compromisso com o desenvolvimento } \\
\text { comunitário /com a gestão social }\end{array}$ & $\begin{array}{l}\text { - Comprometimento dos associados com o } \\
\text { desenvolvimento da AABB em relação às ações sociais na } \\
\text { comunidade }\end{array}$ \\
\hline ETHOS & $\begin{array}{l}\text { Gestão dos impactos da empresa na } \\
\text { comunidade }\end{array}$ & $\begin{array}{l}\text { - Impactos perceptíveis na comunidade com as ações } \\
\text { sociais desenvolvidas }\end{array}$ \\
\hline
\end{tabular}

Fonte: Elaborado pelo autor.

O quadro 4 apresenta oito indicadores das AABBs. Nesta dimensão, o modelo $S D$ não apresenta parâmetro com os indicadores das AABBs. O modelo do Instituto Ethos demonstra a maior relação com os indicadores potenciais do clube. As questões ambientais não fazem parte do "Projeto Diagnóstico das AABBs - 2013" utilizado pela FENABB, tendo sido relacionadas com base nos indicadores dos três modelos selecionados conf. quadro 5.

Quadro 5 - Correlação dos indicadores da dimensão ambiental

\begin{tabular}{|l|l|l|}
\hline Modelo & Indicadores - Dimensão Ambiental & \multicolumn{1}{c|}{ Indicadores das AABBs } \\
\hline GRI & Energia & $\begin{array}{l}\text { - Promoção por parte dos gestores, de atitudes } \\
\text { ETHOS }\end{array}$ \\
SD & $\begin{array}{l}\text { Uso sustentáveis para a redução de energia elétrica no clube. } \\
\text { materiais, água, energia } \\
\text { Consumo de energia }\end{array}$ & $\begin{array}{l}\text { - Promoção por parte dos gestores, de atitudes } \\
\text { sustentáveis para a redução do consumo de água no } \\
\text { clube. }\end{array}$ \\
\hline GRI & Efluentes e Resíduos & - Promoção por parte dos gestores, de atitudes \\
\hline
\end{tabular}




\begin{tabular}{|l|l|l|}
\hline $\begin{array}{l}\text { ETHOS } \\
\text { SD }\end{array}$ & $\begin{array}{l}\text { Impacto decorrente do uso dos } \\
\text { produtos ou serviços } \\
\text { Geração e gestão de lixo }\end{array}$ & $\begin{array}{l}\text { sustentáveis para a correta separação e coleta do lixo } \\
\text { produzido no clube }\end{array}$ \\
\hline ETHOS & $\begin{array}{l}\text { Educação/ conscientização } \\
\text { ambiental }\end{array}$ & $\begin{array}{l}\text { - Promoção de campanhas, projetos e programas } \\
\text { ambientais voltados para os associados e a comunidade. }\end{array}$ \\
\hline ETHOS & $\begin{array}{l}\text { Gestão dos impactos da empresa } \\
\text { na comunidade }\end{array}$ & $\begin{array}{l}\text { - Impactos perceptíveis na comunidade com as ações } \\
\text { ambientais desenvolvidas pela AABB }\end{array}$ \\
\hline ETHOS & $\begin{array}{l}\text { Educação/ conscientização } \\
\text { ambiental }\end{array}$ & $\begin{array}{l}\text { - Compromisso com o desenvolvimento da comunidade } \\
\text { em relação às ações ambientais (projetos permanentes) }\end{array}$ \\
\hline GRI & $\begin{array}{l}\text { Avaliação ambiental de } \\
\text { fornecedores }\end{array}$ & $\begin{array}{l}\text { - Definição de fornecedores em razão de suas práticas } \\
\text { ambientais }\end{array}$ \\
\hline
\end{tabular}

Fonte: Elaborado pelo autor.

Os indicadores das AABBs nas três dimensões, totalizam 21 e, como alguns são correlacionados com mais de um modelo a proporcionalidade apresenta os valores percentuais de $66 \%$ com os indicadores do Instituto Ethos, $29 \%$ com os indicadores do Global Reporting Initiative e $19 \%$ com os indicadores do Dashboard of sustainability.

\section{Resultados}

Foram calculadas as frequências para cada pergunta respondida, bem como a frequência média de cada variável e o valor percentual, considerando o total das frequências nos fatores 1 e 2 (insatisfeito e pouco satisfeito), 3 (indiferente) e 4 e 5 (satisfeito e muito satisfeito). Os resultados foram confrontados entre os dirigentes e os associados por dimensão, de forma que fosse possível comparar e analisar as percepções entre eles no contexto geral das cinco regiões conforme demonstrado na Tabela 2.

Tabela 2 - Frequências, médias, percentuais - associados e dirigentes - dimensão social.

\begin{tabular}{|c|c|c|c|c|c|c|c|}
\hline DS & ASSOCIADOS / DIMENSÃO SOCIAL & 1 & 2 & 3 & 5 & $\mathrm{~V}$ & M. \\
\hline \multirow{2}{*}{ DS1 } & \multirow{2}{*}{ Excelência no atendimento aos associados } & 21 & 53 & 113 & \begin{tabular}{|l|l|}
191 & 125 \\
\end{tabular} & 2 & 3,8 \\
\hline & & \multicolumn{2}{|c|}{$15 \%$} & $22 \%$ & $63 \%$ & - & - \\
\hline \multirow{2}{*}{ DS2 } & \multirow{2}{*}{ Desenvolvimento de atividades sociais } & 31 & 67 & 172 & \begin{tabular}{|l|l|}
154 & 80 \\
\end{tabular} & 1 & 3,6 \\
\hline & & \multicolumn{2}{|c|}{$20 \%$} & $34 \%$ & $46 \%$ & & \\
\hline \multirow{2}{*}{ DS3 } & \multirow{2}{*}{ Desenvolvimento de atividades esportivas } & \multirow{2}{*}{\multicolumn{2}{|c|}{\begin{tabular}{r|r|}
35 & 49 \\
$16 \%$
\end{tabular}}} & 123 & \begin{tabular}{|l|l|}
148 & 146 \\
\end{tabular} & 4 & 3,8 \\
\hline & & & & $25 \%$ & $59 \%$ & & \\
\hline \multirow{2}{*}{ DS4 } & \multirow{2}{*}{ Desenvolvimento de atividades culturais } & 45 & 124 & 170 & \begin{tabular}{|l|l|}
103 & 58 \\
\end{tabular} & 5 & 3,5 \\
\hline & & \multicolumn{2}{|c|}{$34 \%$} & $34 \%$ & $32 \%$ & & \\
\hline \multirow{2}{*}{ DS5 } & \multirow{2}{*}{$\begin{array}{l}\text { Estratégia de comunicação com os associados (jornal, } \\
\text { boletim, internet etc.) }\end{array}$} & 36 & 100 & 134 & \begin{tabular}{|l|l|}
132 & 103 \\
\end{tabular} & & 3,7 \\
\hline & & \multicolumn{2}{|c|}{$27 \%$} & $27 \%$ & $46 \%$ & & \\
\hline \multirow{2}{*}{ DS6 } & \multirow{2}{*}{$\begin{array}{l}\text { Comprometimento dos associados com o desenvolvimento } \\
\text { da AABB em relação às ações sociais perante a comunidade }\end{array}$} & 38 & 118 & 189 & \begin{tabular}{|l|l|}
111 & 48 \\
\end{tabular} & 1 & 3,4 \\
\hline & & \multicolumn{2}{|c|}{$31 \%$} & $38 \%$ & $32 \%$ & & \\
\hline \multirow{2}{*}{ DS7 } & \multirow{2}{*}{$\begin{array}{l}\text { Promoção de campanhas, projetos e programas educativos } \\
\text { voltados para associados e comunidade }\end{array}$} & & 130 & 139 & \begin{tabular}{|l|l|}
130 & 54 \\
\end{tabular} & & 3,5 \\
\hline & & \multicolumn{2}{|c|}{$36 \%$} & $28 \%$ & $36 \%$ & & \\
\hline \multirow{3}{*}{ DS8 } & \multirow{2}{*}{$\begin{array}{l}\text { Impactos perceptíveis na comunidade com as ações sociais } \\
\text { desenvolvidas pela AABB }\end{array}$} & 58 & 128 & 142 & \begin{tabular}{|l|l|}
124 & 51 \\
\end{tabular} & 2 & 3,4 \\
\hline & & \multicolumn{2}{|c|}{$37 \%$} & $28 \%$ & $35 \%$ & & \\
\hline & DIRIGENTES / DIMENSÃO SOCIAL & 1 & 2 & 3 & 5 & $\mathrm{~V}$ & M. \\
\hline \multirow{2}{*}{ DS1 } & \multirow{2}{*}{ Excelência no atendimento aos associados } & 4 & 18 & 70 & \begin{tabular}{|l|l|}
90 & 40 \\
\end{tabular} & & 3,6 \\
\hline & & & $\%$ & $32 \%$ & $58 \%$ & & \\
\hline DS2 & Desenvolvimento de atividades sociais & 10 & 42 & 86 & \begin{tabular}{|l|l|}
59 & 25 \\
\end{tabular} & & 3,2 \\
\hline & & & $\%$ & $39 \%$ & $38 \%$ & & \\
\hline DS3 & Desenvolvimento de atividades esportivas & 3 & 31 & 45 & \begin{tabular}{|l|l|}
86 & 57 \\
\end{tabular} & & 3,7 \\
\hline
\end{tabular}


PRÁTICAS SUSTENTÁVEIS DE INOVAÇÃO PARA TOMADA DE DECISÃO BASEADA NA PERCEPÇÃO DE GESTORES E ASSOCIADOS: UM ESTUDO NAS ASSOCIAÇÕES ATLÉTICAS DO BANCO DO BRASIL

\begin{tabular}{|c|c|c|c|c|c|c|}
\hline & & \multicolumn{2}{|c|}{$15 \%$} & $20 \%$ & $65 \%$ & \multirow[b]{2}{*}{2,7} \\
\hline \multirow{2}{*}{ DS4 } & \multirow{2}{*}{ Desenvolvimento de atividades culturais } & 34 & 65 & 68 & \begin{tabular}{|l|l|}
42 & 13 \\
\end{tabular} & \\
\hline & & \multicolumn{2}{|c|}{$45 \%$} & $31 \%$ & $24 \%$ & \\
\hline \multirow{2}{*}{ DS5 } & \multirow{2}{*}{$\begin{array}{l}\text { Estratégia de comunicação com os associados (jornal, } \\
\text { boletim, internet etc.) }\end{array}$} & 27 & 68 & 59 & \begin{tabular}{|l|l|}
55 & 13 \\
\end{tabular} & 2,8 \\
\hline & & \multicolumn{2}{|c|}{$43 \%$} & $26 \%$ & $31 \%$ & \\
\hline \multirow{2}{*}{ DS6 } & \multirow{2}{*}{$\begin{array}{l}\text { Comprometimento dos associados com o desenvolvimento } \\
\text { da AABB em relação às ações sociais perante a comunidade }\end{array}$} & 32 & 63 & 73 & \begin{tabular}{|l|l|}
45 & 9 \\
\end{tabular} & 2,7 \\
\hline & & \multicolumn{2}{|c|}{$43 \%$} & $33 \%$ & $24 \%$ & \\
\hline \multirow{2}{*}{ DS7 } & \multirow{2}{*}{$\begin{array}{l}\text { Promoção de campanhas, projetos e programas educativos } \\
\text { voltados para associados e comunidade }\end{array}$} & 24 & 71 & 81 & 41 & 2,6 \\
\hline & & \multicolumn{2}{|c|}{$43 \%$} & $36 \%$ & $21 \%$ & \\
\hline \multirow{2}{*}{ DS8 } & \multirow{2}{*}{$\begin{array}{l}\text { Impactos perceptíveis na comunidade com as ações sociais } \\
\text { desenvolvidas pela AABB }\end{array}$} & 24 & 40 & 75 & 20 & 3,0 \\
\hline & & \multicolumn{2}{|c|}{$29 \%$} & $34 \%$ & $37 \%$ & \\
\hline
\end{tabular}

Fonte: Elaborada pelo autor.

Na análise dos dados apresentados na Tabela 2 em relação à dimensão social baseada no atendimento e na interação dos associados, dirigentes e a comunidade, Martins e Cândido (2015) afirmam que a sustentabilidade passa pela possibilidade de mudanças, sejam de valores, crenças, atitudes, comportamentos, modo de agir e de se relacionar em uma perspectiva individual e, principalmente, coletiva, mediante valores éticos desprovidos de comportamento individualista ou corporativo.

O Gráfico 1, demonstra que há uma tendência nos fatores "satisfeito e muito satisfeito" nas respostas dos associados às perguntas DS1 e DS3, registrando percentuais acima de $50 \%$. No que se refere aos fatores "insatisfeito e pouco satisfeito", as questões DS7 e DS8 registraram os maiores índices percentuais, $36 \%$ e $37 \%$, respectivamente.

Gráfico 1 - Representação dos percentuais das respostas dos associados - Dimensão social

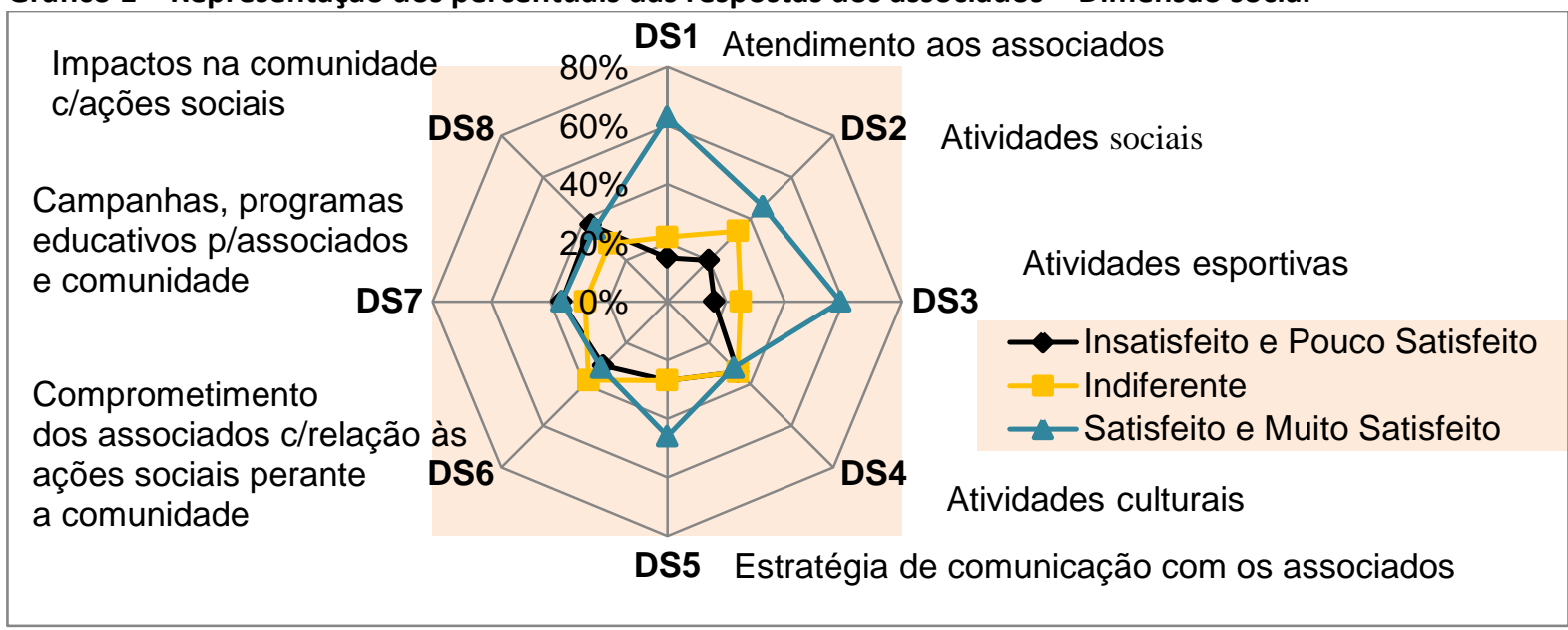

Fonte: Dados da pesquisa.

Os índices nos fatores "insatisfeito e pouco satisfeito" das perguntas DS7 (Campanhas, projetos e programas educativos para associados e comunidade) e DS8 (impactos na comunidade com ações sociais), indicam a necessidade de ações mais efetivas nas AABBs em relação ao envolvimento e participação de ações nas comunidades. $O$ fator "indiferente" representa uma situação que demonstra pouco interesse por parte dos associados. O Gráfico 2 demonstra a percepção dos dirigentes em relação às mesmas perguntas na dimensão social.

Gráfico 2 - Representação dos percentuais das respostas dos dirigentes - Dimensão social 


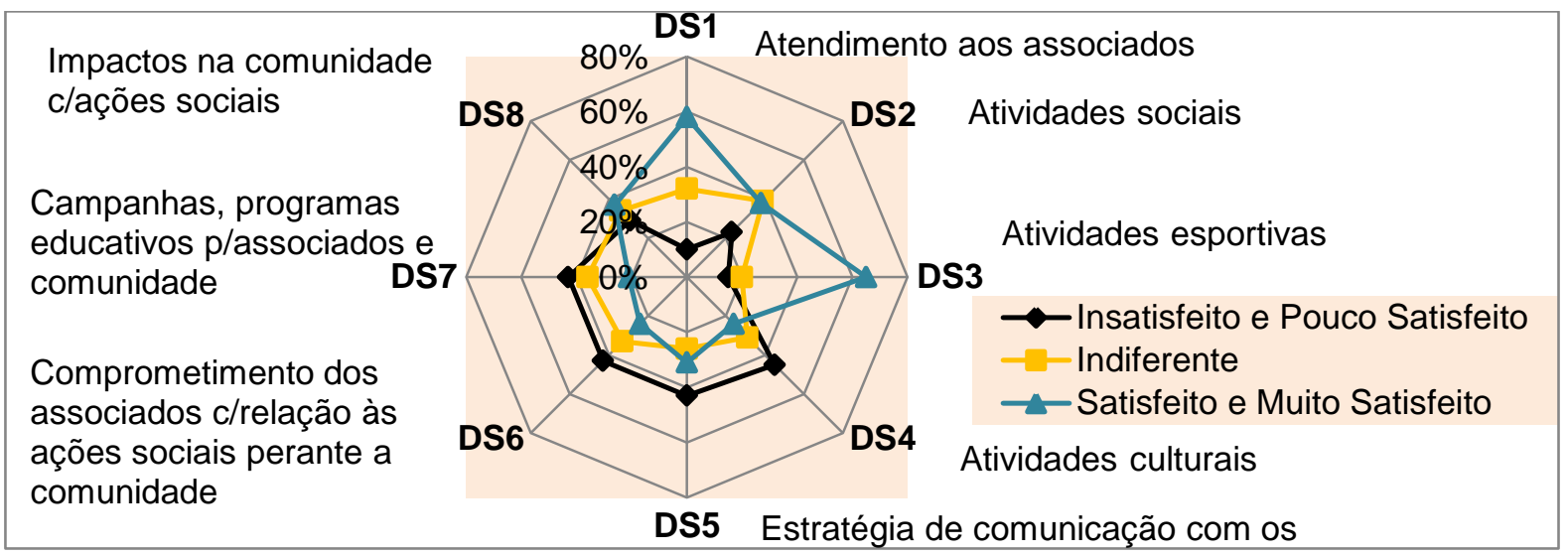

Fonte: Dados da pesquisa.

As respostas dos dirigentes demonstram sintonia com os associados nas questões relacionadas à excelência no atendimento (DS1) e ao desenvolvimento de atividades esportivas (DS3), apresentando valores percentuais acima de $50 \%$. No que se refere aos fatores "insatisfeito e pouco satisfeito", os dirigentes são mais críticos. O fator "indiferente" apresentou maior percentual entre os demais fatores na pergunta DS2 (Desenvolvimento de atividades sociais), registrando $39 \%$. Esse resultado entre os dirigentes pode ser interpretado como um indício de acomodação em relação às atividades promovidas pelo clube para os associados, evidenciando falta de interesse em propor eventos que estimulem maior participação dos associados. Há uma tendência natural em satisfação e fidelização quando o serviço recebido pelo cliente excede aquilo que se espera (ZEITHAML; BITNER, 2003).

A Tabela 3 apresenta a percepção dos associados e dirigentes considerando os fatores relacionados à dimensão ambiental. A pergunta DA7 foi elaborada somente para os dirigentes, em razão de a sua definição ser de alçada do administrador.

Tabela 3 - Frequências, médias, percentuais - associados e dirigentes - dimensão ambiental.

\begin{tabular}{|c|c|c|c|c|c|c|c|c|}
\hline DA & ASSOCIADOS/DIMENSÃO AMBIENTAL & 1 & 2 & 3 & 4 & 5 & V & M. \\
\hline \multirow{2}{*}{ DA1 } & \multirow{2}{*}{$\begin{array}{l}\text { Promoção, por parte dos gestores, de atitudes sustentáveis } \\
\text { para a redução de energia elétrica no clube }\end{array}$} & 48 & 107 & 184 & 111 & 53 & 2 & 3,4 \\
\hline & & \multicolumn{2}{|c|}{$31 \%$} & $37 \%$ & \multicolumn{2}{|c|}{$32 \%$} & & \\
\hline \multirow{2}{*}{ DA2 } & \multirow{2}{*}{$\begin{array}{l}\text { Promoção, por parte dos gestores, de atitudes sustentáveis } \\
\text { para a redução do consumo de água no clube }\end{array}$} & 47 & 111 & 169 & 112 & 66 & & 3,5 \\
\hline & & \multicolumn{2}{|c|}{$31 \%$} & $33 \%$ & \multicolumn{2}{|c|}{$35 \%$} & & \\
\hline \multirow{2}{*}{ DA3 } & \multirow{2}{*}{$\begin{array}{l}\text { Promoção, por parte dos gestores, de atitudes sustentáveis } \\
\text { para a separação e coleta do lixo produzido no clube }\end{array}$} & 46 & 88 & 176 & 141 & 52 & 2 & 3,4 \\
\hline & & \multicolumn{2}{|c|}{$27 \%$} & $35 \%$ & \multicolumn{2}{|c|}{$38 \%$} & & \\
\hline \multirow{2}{*}{ DA4 } & \multirow{2}{*}{$\begin{array}{l}\text { Promoção de campanhas, projetos e programas ambientais } \\
\text { voltados para associados e comunidade (projetos pontuais) }\end{array}$} & 64 & 120 & 167 & 108 & 46 & & 3,3 \\
\hline & & \multicolumn{2}{|c|}{$36 \%$} & $33 \%$ & \multicolumn{2}{|c|}{$31 \%$} & & \\
\hline \multirow{2}{*}{ DA5 } & \multirow{2}{*}{$\begin{array}{l}\text { Impactos perceptíveis na comunidade com as ações } \\
\text { ambientais desenvolvidas pela AABB }\end{array}$} & 67 & 139 & 156 & 98 & 45 & & 3,3 \\
\hline & & \multicolumn{2}{|c|}{$41 \%$} & $31 \%$ & \multicolumn{2}{|c|}{$28 \%$} & & \\
\hline \multirow{2}{*}{ DA6 } & \multirow{2}{*}{$\begin{array}{l}\text { Compromisso com o desenvolvimento da comunidade em } \\
\text { relação às ações ambientais (projetos permanentes) }\end{array}$} & 66 & 134 & 149 & 104 & 52 & & 3,4 \\
\hline & & \multicolumn{2}{|c|}{$40 \%$} & $29 \%$ & \multicolumn{2}{|c|}{$31 \%$} & & \\
\hline $\mathrm{DA}$ & DIRIGENTES/DIMENSÃO AMBIENTAL & 1 & 2 & 3 & 4 & 5 & $\mathrm{~V}$ & M. \\
\hline \multirow{2}{*}{ DA1 } & \multirow{2}{*}{$\begin{array}{l}\text { Promoção, por parte dos gestores, de atitudes sustentáveis } \\
\text { para a redução de energia elétrica no clube }\end{array}$} & 12 & 47 & 73 & 67 & 23 & & 3,1 \\
\hline & & \multicolumn{2}{|c|}{$26 \%$} & $33 \%$ & \multicolumn{2}{|c|}{$41 \%$} & & \\
\hline \multirow{2}{*}{ DA2 } & \multirow{2}{*}{$\begin{array}{l}\text { Promoção, por parte dos gestores, de atitudes sustentáveis } \\
\text { para a redução do consumo de água no clube }\end{array}$} & 10 & 37 & 72 & 79 & 24 & & 3,3 \\
\hline & & \multicolumn{2}{|c|}{$21 \%$} & $32 \%$ & \multicolumn{2}{|c|}{$47 \%$} & & \\
\hline DA3 & Promoção, por parte dos gestores, de atitudes sustentáveis & 24 & 65 & 58 & 56 & 19 & & 2,9 \\
\hline
\end{tabular}



ASSOCIADOS: UM ESTUDO NAS ASSOCIAÇÕES ATLÉTICAS DO BANCO DO BRASIL

\begin{tabular}{|c|c|c|c|c|c|}
\hline & para a separação e coleta do lixo produzido no clube & $40 \%$ & $26 \%$ & $34 \%$ & \multirow[b]{2}{*}{2,6} \\
\hline \multirow{2}{*}{ DA4 } & \multirow{2}{*}{$\begin{array}{l}\text { Promoção de campanhas, projetos e programas ambientais } \\
\text { voltados para associados e comunidade (projetos pontuais) }\end{array}$} & \begin{tabular}{l|l}
36 & 62
\end{tabular} & 68 & \begin{tabular}{|l|l}
51 & 5
\end{tabular} & \\
\hline & & $44 \%$ & $31 \%$ & $25 \%$ & \\
\hline \multirow{2}{*}{ DA5 } & \multirow{2}{*}{$\begin{array}{l}\text { Impactos perceptíveis na comunidade com as ações } \\
\text { ambientais desenvolvidas pela AABB }\end{array}$} & \begin{tabular}{|l|l|}
29 & 57 \\
\end{tabular} & 80 & \begin{tabular}{|l|l|}
42 & 14 \\
\end{tabular} & 2,7 \\
\hline & & $39 \%$ & $36 \%$ & $25 \%$ & \\
\hline \multirow{2}{*}{ DA6 } & \multirow{2}{*}{$\begin{array}{l}\text { Compromisso com o desenvolvimento da comunidade em } \\
\text { relação às ações ambientais (projetos permanentes) }\end{array}$} & \begin{tabular}{l|l}
35 & 52 \\
\end{tabular} & 79 & & 2,7 \\
\hline & & $39 \%$ & $36 \%$ & \begin{tabular}{c|c}
48 & 8 \\
$25 \%$
\end{tabular} & \\
\hline \multirow{2}{*}{ DA7* } & \multirow{2}{*}{$\begin{array}{l}\text { A definição dos fornecedores do clube está relacionada às } \\
\text { boas práticas ambientais }\end{array}$} & \begin{tabular}{l|l}
26 & 52 \\
\end{tabular} & 80 & \begin{tabular}{l|l|}
57 & 7 \\
\end{tabular} & 2,8 \\
\hline & & $35 \%$ & $36 \%$ & $29 \%$ & \\
\hline
\end{tabular}

Fonte: Elaborada pelo autor.

Com base nas perguntas apresentadas na Tabela 5 e a significância da dimensão ambiental, Almeida (2007) relata que é necessário manter a atual tendência em relação aos serviços ambientais que atualmente são gratuitos, pois, em um futuro previsível, esses serviços poderão não estar mais disponíveis ou se tornarão de alto custo, dificultando o ambiente de negócios para todas as empresas.

É fundamental que se estabeleça a inserção de novos conceitos na cultura da organização, exigindo um sistema de comunicação eficiente entre os stakeholders, o qual mobilize todos os seus integrantes em busca da melhoria da qualidade de vida destes e a dos membros da comunidade a que pertencem (VALLE, 2012). Segundo Piga e Mansano (2016) diferentes vertentes ambientais indicam a emergência crescente de uma micropolítica voltada ao campo ambiental.

O Gráfico 3 demonstra a percepção dos associados, evidenciando como é percebida a dimensão ambiental diante dos fatores analisados.

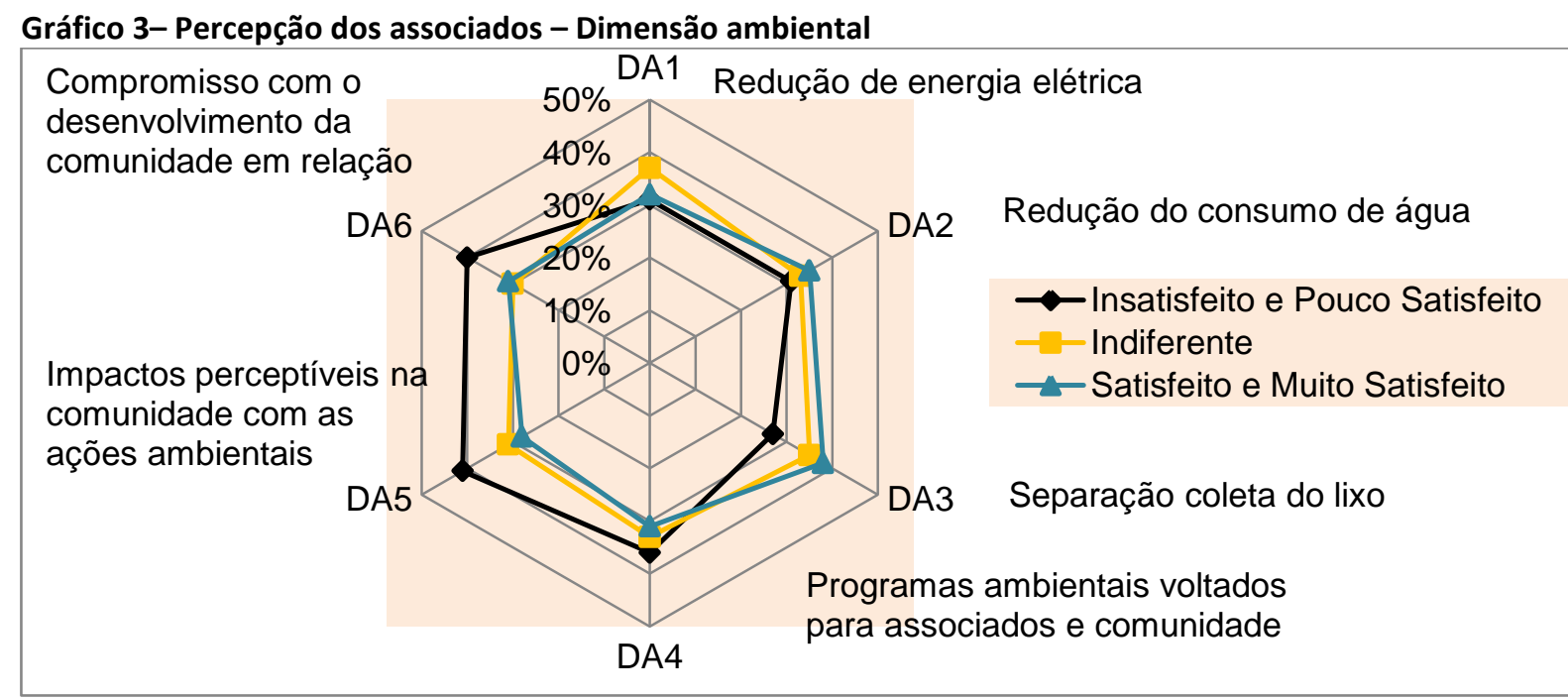

Fonte: Dados da pesquisa.

Nota-se, na representação do Gráfico 7, que os fatores "Insatisfeito e Pouco Satisfeito" sobressaem em três das seis perguntas (DA4 - 36\%, DA5 - 41\% e DA6 - 40\%), demonstrando baixa significância, por parte dos associados, nas questões relacionadas à comunidade na dimensão ambiental. O fator "indiferente" é representativo em todas as perguntas, demonstrando pouco interesse dos associados acerca desse tema. Os fatores "satisfeito e muito satisfeito" apresentam resultados superiores aos demais fatores nas perguntas DS2, e DS3. 
No Gráfico 4 é demonstrada a percepção dos dirigentes em relação a essa mesma dimensão ambiental. Observa-se que na concepção dos dirigentes, as perguntas DA1 Promoção por parte dos gestores, de atitudes sustentáveis para a redução de energia elétrica no clube, e DA2 - Promoção por parte dos gestores, de atitudes sustentáveis para a redução de água no clube, receberam os maiores percentuais, aproximando-se de 50\%; porém, essa avaliação difere da percepção dos associados que responderam com percentual elevado nos fatores "insatisfeito e pouco satisfeito" e no fator "indiferente" essas ações nos clubes.

\section{Gráfico 4 - Percepção dos dirigentes - Dimensão ambiental}

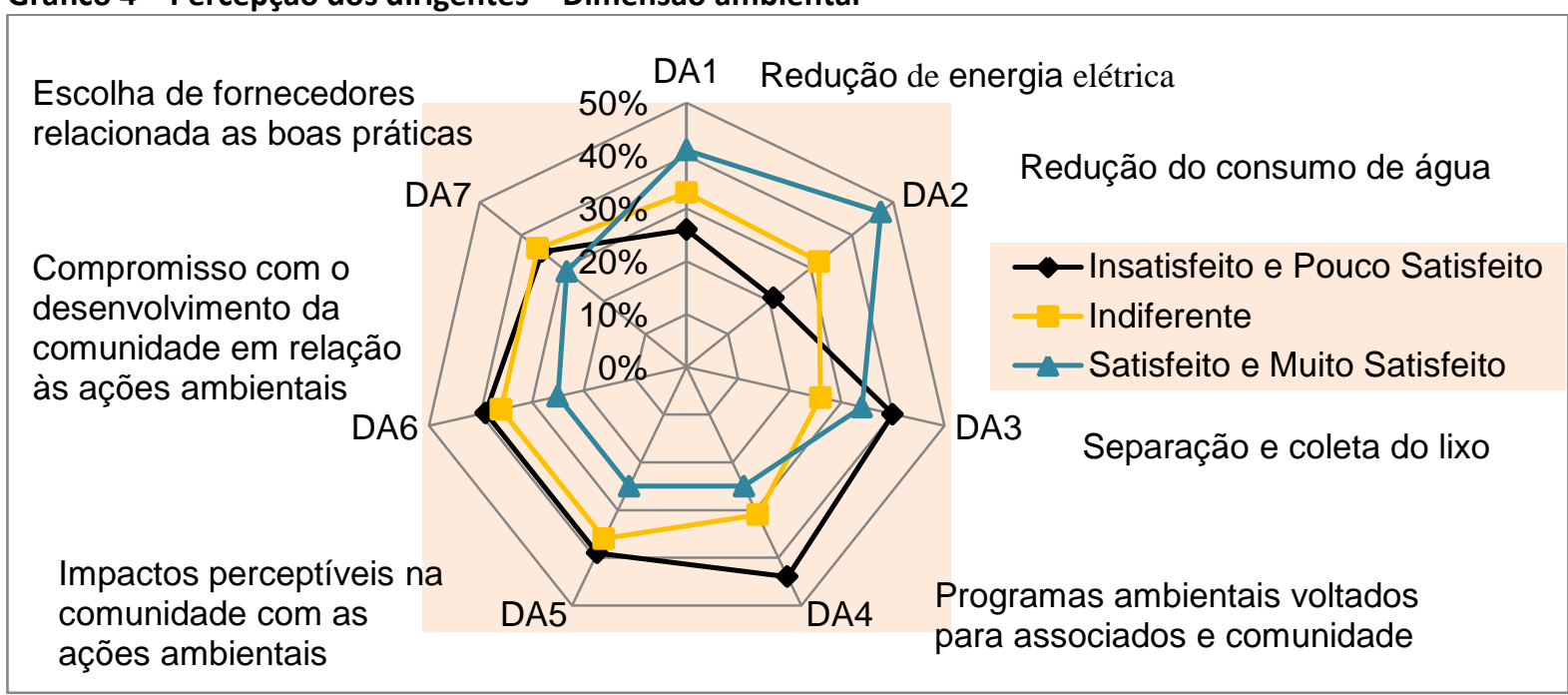

Fonte: Dados da pesquisa.

Assumir a atitude de preservar, reduzir o consumo e, consequentemente, melhorar o desempenho financeiro e econômico dos clubes é atuar com responsabilidade socioambiental sem a necessidade de fazer investimentos. A Lei $n$ ㅇ 9.795, de 27 de abril de 1999, inciso $\mathrm{VI}$, dispõe que a sociedade como um todo deve manter atenção permanente à formação de valores, atitudes e habilidades que propiciem a atuação individual e coletiva voltada para a prevenção, identificação e solução de problemas ambientais.

$\mathrm{Na}$ Tabela 4 são apresentadas as percepções dos associados e dirigentes na dimensão econômica. Nessa dimensão observa-se que os fatores "satisfeito e muito satisfeito" obtiveram os maiores percentuais nas respostas dos associados em relação às perguntas DE4, DE5 e DE6. Essa constatação demonstra que há coerência na cobrança das parcelas mensais comparadas aos demais clubes e compatibilidade entre os valores pagos e os serviços disponibilizados internamente. Evidencia também, na pergunta DE1 Participação dos associados no sistema de gestão, na definição e aperfeiçoamento dos serviços oferecidos pelo clube - que há pouca iniciativa dos dirigentes para envolver os associados nas discussões de serviços e aperfeiçoamento do que é oferecido pelo clube.

Tabela 4 - Frequências, médias, percentuais - associados e dirigentes - dimensão econômica.

\begin{tabular}{c|l|c|c|c|c|c|c|c}
\hline DE & ASSOCIADOS / DIMENSÃO ECONÔMICA & 1 & 2 & 3 & 4 & 5 & V & M. \\
\hline \multirow{2}{*}{ DE1 } & Participação dos associados no sistema de gestão, & 52 & 124 & 197 & 85 & 47 & & 3,3 \\
\cline { 3 - 10 } & definição e aperfeiçoamento dos serviços oferecidos & \multicolumn{2}{|c|}{$35 \%$} & $39 \%$ & \multicolumn{2}{|c|}{$26 \%$} & & \\
\hline \multirow{2}{*}{ DE2 } & \multirow{2}{*}{ Performance da Governança da AABB } & 31 & 60 & 164 & 156 & 90 & 4 & 3,6 \\
\cline { 3 - 10 } & & \multicolumn{2}{|c|}{$18 \%$} & $33 \%$ & $49 \%$ & & \\
\hline
\end{tabular}



ASSOCIADOS: UM ESTUDO NAS ASSOCIAÇÕES ATLÉTICAS DO BANCO DO BRASIL

\begin{tabular}{|c|c|c|c|c|c|c|c|c|}
\hline \multirow{2}{*}{ DE3 } & \multirow{2}{*}{ Investimento na infraestrutura do clube } & \multirow{2}{*}{\multicolumn{2}{|c|}{\begin{tabular}{l|l}
59 & 81 \\
$28 \%$ \\
\end{tabular}}} & 137 & 134 & 94 & & 3,5 \\
\hline & & & & $27 \%$ & \multicolumn{2}{|c|}{$45 \%$} & & \\
\hline \multirow{2}{*}{ DE4 } & \multirow{2}{*}{$\begin{array}{l}\text { O valor da mensalidade é compatível com os serviços } \\
\text { oferecidos pelo clube }\end{array}$} & 35 & 62 & 136 & 137 & 134 & 1 & 3,7 \\
\hline & & \multicolumn{2}{|c|}{$19 \%$} & $27 \%$ & \multicolumn{2}{|c|}{$54 \%$} & & \\
\hline \multirow{2}{*}{ DE5 } & \multirow{2}{*}{$\begin{array}{l}\text { O valor da mensalidade é compatível com relação aos } \\
\text { clubes da região }\end{array}$} & 17 & 41 & 142 & 156 & 149 & & 3,9 \\
\hline & & \multicolumn{2}{|c|}{$11 \%$} & $28 \%$ & \multicolumn{2}{|c|}{$60 \%$} & & \\
\hline \multirow[b]{2}{*}{ DE6 } & \multirow{2}{*}{$\begin{array}{l}\text { O valor pago pelos associados (não incluso na } \\
\text { mensalidade) em eventos, como shows musicais, } \\
\text { apresentações artísticas etc., programados pelo clube } \\
\text { é adequado e coerente }\end{array}$} & 35 & 53 & 124 & 105 & 184 & 4 & 3,6 \\
\hline & & \multicolumn{2}{|c|}{$17 \%$} & $25 \%$ & \multicolumn{2}{|c|}{$58 \%$} & & \\
\hline $\mathrm{DE}$ & DIRIGENTES / DIMENSÃO ECONÔMICA & 1 & 2 & 3 & 4 & 5 & $\mathrm{~V}$ & M. \\
\hline \multirow{2}{*}{ DE1 } & \multirow{2}{*}{$\begin{array}{l}\text { Participação dos associados no sistema de gestão, } \\
\text { definição e aperfeiçoamento dos serviços oferecidos }\end{array}$} & 33 & 51 & 79 & 52 & 7 & & 2,7 \\
\hline & & \multicolumn{2}{|c|}{$38 \%$} & $36 \%$ & \multicolumn{2}{|c|}{$26 \%$} & & \\
\hline \multirow{2}{*}{ DE2 } & \multirow{2}{*}{ Performance da Governança da AABB } & 13 & 45 & 76 & 67 & 21 & & 3,1 \\
\hline & & \multicolumn{2}{|c|}{$26 \%$} & $34 \%$ & \multicolumn{2}{|c|}{$40 \%$} & & \\
\hline \multirow{2}{*}{ DE3 } & \multirow{2}{*}{ Investimento na infraestrutura do clube } & & 38 & 53 & 69 & 50 & & 3,4 \\
\hline & & \multicolumn{2}{|c|}{$22 \%$} & $24 \%$ & \multicolumn{2}{|c|}{$54 \%$} & & \\
\hline \multirow{2}{*}{ DE4 } & \multirow{2}{*}{$\begin{array}{l}\text { O valor da mensalidade é compatível com os serviços } \\
\text { oferecidos pelo clube }\end{array}$} & 6 & 25 & 68 & 71 & 52 & & 3,6 \\
\hline & & \multicolumn{2}{|c|}{$14 \%$} & $31 \%$ & \multicolumn{2}{|c|}{$55 \%$} & & \\
\hline \multirow{2}{*}{ DE5 } & \multirow{2}{*}{$\begin{array}{l}\text { O valor da mensalidade é compatível com relação aos } \\
\text { clubes da região }\end{array}$} & 9 & 25 & 61 & 77 & 50 & & 3,6 \\
\hline & & 15 & $\%$ & $27 \%$ & & & & \\
\hline & O valor pago pelos associados (não incluso na & 14 & 22 & 63 & 70 & 53 & & 3,5 \\
\hline DE6 & $\begin{array}{l}\text { mensalıade) em eventos, como shows musicals, } \\
\text { apresentações artísticas etc., programados pelo clube } \\
\text { é adequado e coerente }\end{array}$ & & $\%$ & $28 \%$ & & & & \\
\hline
\end{tabular}

Fonte: Elaborada pelo autor.

No entendimento de Dias, Zavaglia e Cassar (2013), os desafios que se apresentam na administração moderna requerem das organizações posicionamentos inovadores, não sendo possível ignorar que os problemas devem ser enfrentados e discutidos com soluções integradas entre gestores e colaboradores, confrontando saberes múltiplos direcionados e combinados para um fim comum.

Chiavenato (2003) corrobora afirmando que a administração participativa e democrática precisa sobrepor a administração autocrática para que seja possível um desempenho eficaz para inovar e resolver problemas operacionais com liberdade, autoridade e responsabilidade através do esforço coletivo e do trabalho em equipe. Com a integração de associados e dirigentes na administração econômico-financeira dos clubes, certamente, o nível de comprometimento de todos os envolvidos atingirá números elevados na análise de desempenho da instituição fortalecendo todas as demais áreas internas. 0 Gráfico 5 demonstra a percepção dos associados nesta dimensão.

Gráfico 5 - Percepção dos associados - Dimensão econômica 


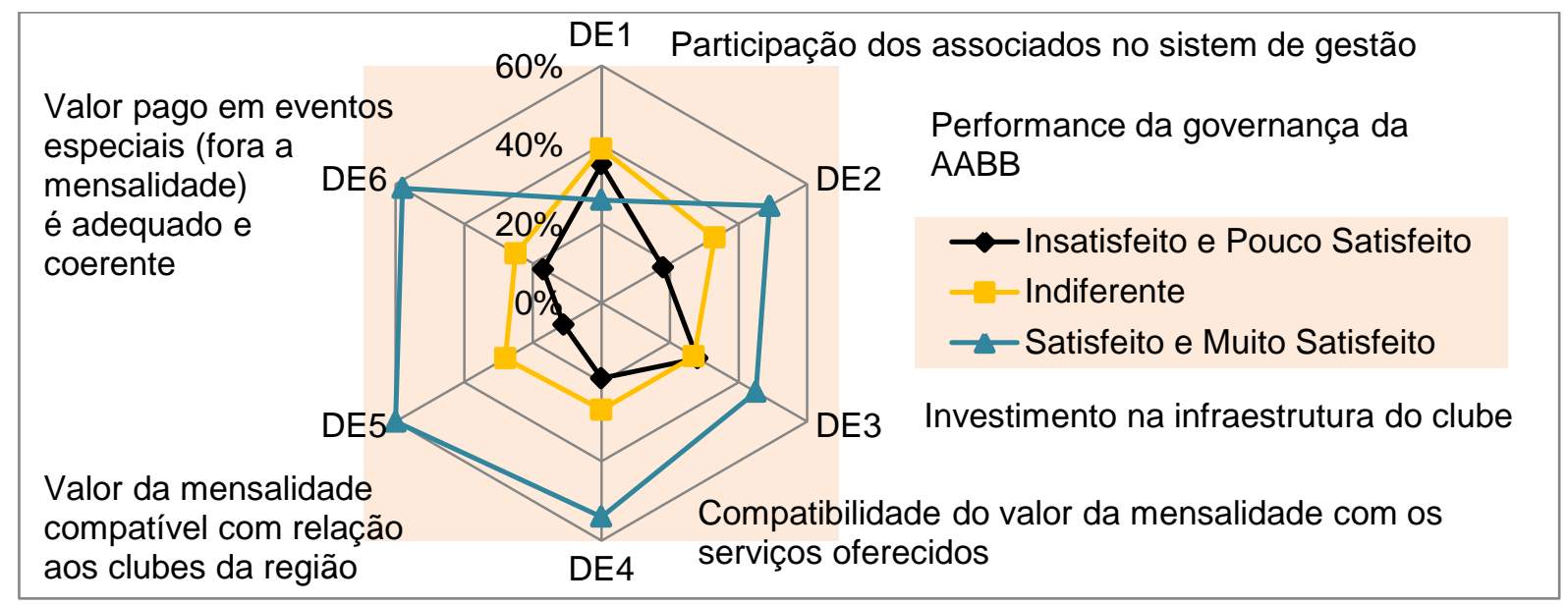

Fonte: Dados da pesquisa.

A demonstração do Gráfico 5 evidencia a percepção dos associados nas questões que envolvem a participação na gestão, investimentos na estrutura dos clubes e valores pagos relacionados aos serviços oferecidos e os valores cobrados pela concorrência externa. A percepção dos dirigentes na dimensão econômica é demostrada no Gráfico 6, no qual é possível perceber similaridade com as respostas dos associados.

Gráfico 6 - Percepção dos dirigentes - Dimensão econômica

Valor pago em
eventos especiais
(fora a mensalidade) é
adequado e coerentê6

Fonte: Dados da pesquisa.

Nessa dimensão, os dirigentes apresentam valores percentuais acima de $50 \%$ nas perguntas DE3, DE4, DE5 e DE6, confirmando as expectativas dos associados e menor valor percentual (26\%) na pergunta DE1 - Participação dos associados no sistema de gestão, definição e aperfeiçoamento dos serviços oferecidos pelo clube -, registrando, também, coerência com a percepção dos associados. Nessa pergunta, os fatores "insatisfeito e pouco satisfeito" e o fator "indiferente" apresentaram percentuais de 38\% e 36\% respectivamente.

Silva e Wiens (2010) definem a participação coletiva no sistema de gestão como meio de organizar pessoas para atingir objetivos comuns, gerando resultados satisfatórios para a instituição na criação de uma cultura de grupo comprometido com os resultados. Esse resultado demonstra, por parte dos associados, que pode estar havendo resistência dos dirigentes em administrar o clube de forma participativa. Entretanto, na perspectiva dos dirigentes, o fator "insatisfeito e pouco satisfeito" pode ser entendido como falta de interesse dos associados em participar das tomadas decisões. O fato é que a 
inexpressividade da administração participativa nos clubes, seja por resistência administrativa ou por falta de interesse dos associados, é predominante.

O Gráfico 7 apresenta, comparativamente, a distribuição das médias das frequências entre associados e dirigentes relacionadas a cada pergunta.

Gráfico 7 - Média das respostas dos associados e dirigentes

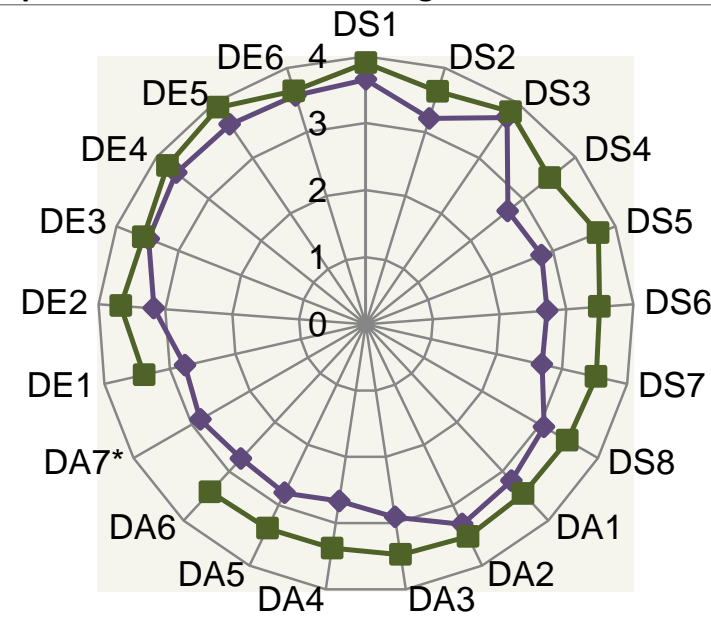

- Dirigentes

-Associados

Fonte: Dados da pesquisa.

Pode-se observar que, em todas as dimensões (DS1 a DE6), a média igual e maior $(\geq)$ de " 3 " se manteve em quase todas as respostas, registrando a tendência de "indiferente" para "satisfeito" com maior intensidade entre os associados. Na dimensão ambiental, a pergunta (DA7) - Definição de fornecedores do clube relacionada às boas práticas ambientais - foi direcionada somente aos dirigentes por se tratar de decisão administrativa que cabe ao conselho diretivo dos clubes. A dimensão econômica mostra paridade nas médias, com pequenas variações em ambos os respondentes (associados e dirigentes), com exceção das perguntas DE1 - com médias de 3,3 entre associados e de 2,7 entre dirigentes e a pergunta DE2 - com médias de 3,6 entre associados e de 3,1 entre dirigentes.

\section{Análise fatorial dos dados}

A análise fatorial é uma combinação de procedimentos utilizados, essencialmente, para redução e resumo dos dados existentes em uma pesquisa (MALHOTRA, 2012). O objetivo da análise neste trabalho foi encontrar uma maneira de condensar as informações contidas nas variáveis originais em um grupo menor de variáveis (fatores) com a perda mínima de informação possível no grupo dos associados e dos dirigentes.

A análise da correlação indica que, quanto mais perto de -1 (positivo ou negativo), maior será o grau de dependência estatística linear entre as variáveis, assim como, quanto mais próximo de zero, menor será a força dessa relação (FIGUEIREDO FILHO; SILVA JÚNIOR, 2010). A Tabela 5 apresenta as correlações entre as variáveis para o grupo dos associados.

Tabela 5 - Correlação entre as variáveis para o grupo - associados. 


\begin{tabular}{|c|c|c|c|c|c|c|c|c|c|c|c|c|c|c|c|c|c|c|c|c|}
\hline & DS1 & $\mathrm{DS} 2$ & DS3 & DS4 & DS5 & DS6 & DS7 & DS8 & DA1 & $\mathrm{DA} 2$ & $\mathrm{DA} 3$ & DA4 & DA5 5 & DA6 & DE1 & $\mathrm{DE} 2$ & $\mathrm{DE} 3$ & $\mathrm{DE} 4$ & DE 5 & DE6 \\
\hline DS1 & 1,00 & & & & & & & & & & & & & & & & & & & \\
\hline DS2 & 0,68 & 1,00 & & & & & & & & & & & & & & & & & & \\
\hline DS3 & 0,60 & 0,70 & 1,00 & & & & & & & & & & & & & & & & & \\
\hline DS4 & 0,58 & 0,75 & 0,64 & 1,00 & & & & & & & & & & & & & & & & \\
\hline DS5 & 0,58 & 0,64 & 0,50 & 0,69 & $1,0 \mathrm{~d}$ & & & & & & & & & & & & & & & \\
\hline DS6 & 0,50 & 0,63 & 0,50 & 0,67 & 0,63 & 1,00 & & & & & & & & & & & & & & \\
\hline DS7 & 0,56 & 0,69 & 0,54 & 0,76 & 0,6 & 0,74 & 1,00 & & & & & & & & & & & & & \\
\hline DS8 & 0,55 & 0,66 & 0,56 & 0,72 & 0,63 & 0,75 & 0,80 & 1,00 & & & & & & & & & & & & \\
\hline DAl & 0,52 & 0,63 & 0,52 & 0,62 & 0,59 & 0,61 & 0,61 & 0,72 & 1,00 & & & & & & & & & & & \\
\hline DA2 & 0,51 & 0,61 & 0,50 & 0,59 & 0,53 & 0,58 & 0,58 & 0,69 & 0,89 & 1,00 & & & & & & & & & & \\
\hline DA3 & 0,52 & 0,59 & 0,48 & 0,61 & 0,58 & 0,61 & 0,61 & 0,64 & 0,74 & 0,75 & 1,00 & & & & & & & & & \\
\hline DA4 & 0,53 & 0,62 & 0,51 & 0,71 & 0,65 & 0,71 & 0,71 & 0,78 & 0,73 & 0,69 & 0,75 & 1,00 & & & & & & & & \\
\hline DA5 & 0,48 & 0,58 & 0,46 & 0,66 & 0,59 & 0,68 & 0,71 & 0,76 & 0,73 & 0,74 & 0,75 & 0,84 & 1,00 & & & & & & & \\
\hline DA6 & 0,52 & 0,63 & 0,50 & 0,73 & 0,64 & 0,70 & 0,73 & 0,78 & 0,72 & 0,70 & 0,76 & 0,87 & 0,89 & 1,00 & & & & & & \\
\hline DEl & 0,55 & 0,60 & 0,49 & 0,62 & 0,60 & 0,66 & 0,65 & 0,67 & 0,65 & 0,63 & 0,67 & 0,73 & 0,70 & 0,71 & 1,00 & & & & & \\
\hline $\mathrm{DE} 2$ & 0,68 & 0,70 & 0,64 & 0,63 & 0,61 & 0,64 & 0,64 & 40,65 & 0,68 & 0,65 & 0,66 & 0,68 & 0,64 & 0,64 & 0,69 & 1,00 & & & & \\
\hline $\mathrm{DE} 3$ & 0,52 & 0,61 & 0,56 & 0,59 & 0,56 & 0,52 & 0,55 & 0,61 & 0,60 & 0,59 & 0,59 & 0,56 & 0,55 & 0,60 & 0,58 & 0,71 & 1,00 & & & \\
\hline $\mathrm{DE} 4$ & 0,48 & 0,49 & 0,54 & 0,45 & 0,43 & 0,44 & 0,43 & 0,49 & 0,55 & 0,52 & 0,46 & $0,4 \mathrm{~d}$ & 0,47 & 0,47 & 0,48 & 0,57 & 0,60 & 1,00 & & \\
\hline $\begin{array}{l}\text { DE5 } \\
\text { DE6 }\end{array}$ & \begin{tabular}{|l|}
0,51 \\
0,45 \\
\end{tabular} & $\frac{0,50}{0,53}$ & \begin{tabular}{|l|}
0,57 \\
0,52
\end{tabular} & 0,44 & $\frac{0,44}{0,50}$ & \begin{tabular}{|l|}
0,39 \\
0,47
\end{tabular} & \begin{tabular}{|l|}
0,43 \\
0,49 \\
\end{tabular} & $\begin{array}{l}0,43 \\
0,54\end{array}$ & \begin{tabular}{|l|l|}
0,49 \\
0,55
\end{tabular} & \begin{tabular}{|l|}
0,47 \\
0,55
\end{tabular} & \begin{tabular}{|l|l|}
0,45 \\
0,48
\end{tabular} & $\frac{0,42}{0.53}$ & \begin{tabular}{|l|}
0,42 \\
0,52
\end{tabular} & \begin{tabular}{|l|}
0,44 \\
0,54 \\
\end{tabular} & $\frac{0,47}{0,52}$ & \begin{tabular}{|l|}
0,59 \\
0,58
\end{tabular} & \begin{tabular}{|l|}
0,60 \\
0,57 \\
\end{tabular} & \begin{tabular}{|l|}
0,80 \\
0,67
\end{tabular} & \begin{tabular}{|l|}
1,00 \\
0,65
\end{tabular} & \begin{tabular}{|l|} 
\\
1.00 \\
\end{tabular} \\
\hline
\end{tabular}

Nos dados obtidos na Tabela 5, percebe-se que as correlações no grupo associados - , apresentam elementos relativamente altos entre as variáveis de mesmo âmbito, indicando a possibilidade de que tais variáveis meçam algo em comum, isto é, que essas variáveis sejam ligadas a um mesmo constructo.

Em relação aos dirigentes, a Tabela 6 apresenta as correlações obtidas para o grupo dirigentes, demonstrando que nem todas são relativamente altas entre âmbitos, isto é, as variáveis DS1, DS8, DE1, DE4, DE5 e DE6 possuem baixa correlação com as demais variáveis de seu bloco.

$\mathrm{Na}$ concepção de Hair et al. (2005), se o coeficiente de correlação é estatisticamente significativo, deve-se rejeitar a hipótese nula e concluir, com segurança, que as variáveis examinadas compartilham algum tipo de associação na população pesquisada.

Tabela 6 - Correlação entre as variáveis para o grupo - dirigentes. 


\begin{tabular}{|c|c|c|c|c|c|c|c|c|c|c|c|c|c|c|c|c|c|c|c|c|c|}
\hline & DS1I & $\mathrm{DM}$ & DS3 & & DS5. & DS6 & DS7 & DS8 & DA1 & $\mathrm{DA} 2$ & $\mathrm{DA}_{3}$ & DA4 & $\mathrm{DA} 5$ & DA6 & DA7 & $\mathrm{DE} 1$ & & $\mathrm{DE} 3$ & $\mathrm{DE} 4$ & DES & DE6 \\
\hline DS1 & 1 & & & & & & & & & & & & & & & & & & & & \\
\hline DS2 & 0,45 & 1 & & & & & & & & & & & & & & & & & & & \\
\hline DS3 & 0,44 & 0,56 & 1 & & & & & & & & & & & & & & & & & & \\
\hline DS4 & 0,36 & 0,67 & 0,43 & 1 & & & & & & & & & & & & & & & & & \\
\hline DS5 & 0,31 & 0,51 & 0,48 & 0,52 & 1 & & & & & & & & & & & & & & & & \\
\hline DS6 & 0,40 & 0,51 & 0,45 & 0,55 & 0,64 & 1 & & & & & & & & & & & & & & & \\
\hline DS7 & 0,37 & 0,56 & 0,52 & 0,51 & 0,61 & 0,67 & \begin{tabular}{|l|}
1 \\
\end{tabular} & & & & & & & & & & & & & & \\
\hline DS8 & 0,20 & 0,49 & 0,33 & 0,5 & 0,35 & 0,5 & 0,65 & 1 & & & & & & & & & & & & & \\
\hline DAl & 0,38 & 0,32 & 0,32 & 0,27 & 0,37 & 0,43 & 0,39 & 0,28 & 1 & & & & & & & & & & & & \\
\hline $\mathrm{DA} 2$ & 0,35 & 0,34 & 0,28 & 0,31 & 0,34 & 0,41 & 0,41 & 0,28 & 0,82 & 1 & & & & & & & & & & & \\
\hline $\mathrm{DA} 3$ & 0,30 & 0,24 & 0,19 & 0,35 & 0,36 & 0,44 & 0,32 & 0,27 & 0,58 & 0,6 & 1 & & & & & & & & & & \\
\hline $\mathrm{DA4}$ & 0,35 & 0,58 & 0,45 & 0,59 & 0,56 & 0,6 & 0,66 & 0,51 & 0,45 & 0,46 & 0,57 & 1 & & & & & & & & & \\
\hline DA5 & 0,34 & 0,48 & 0,38 & 0,53 & 0,48 & 0,58 & 0,59 & 0,58 & 0,46 & 0,48 & 0,57 & 0,79 & 1 & & & & & & & & \\
\hline DA6 & 0,31 & 0,44 & 0,43 & 0,52 & 0,46 & 0,53 & 0,56 & 0,59 & 0,48 & 0,5 & 0,55 & 0,74 & 0,83 & 1 & & & & & & & \\
\hline DA7 & 0,33 & 0,44 & 0,44 & 0,45 & 0,47 & 0,55 & 0,5 & 0,38 & 0,48 & 0,48 & 0,49 & 0,68 & 0,64 & 0,69 & 1 & & & & & & \\
\hline $\mathrm{DEl}$ & 0,39 & 0,32 & 0,4 & 0,39 & 0,48 & 0,55 & 0,45 & 0,28 & 0,51 & 0,52 & 0,5 & 0,54 & 0,49 & 0,48 & 0,68 & 1 & & & & & \\
\hline $\mathrm{DE} 2$ & 0,4 & 0,33 & 0,46 & 0,32 & 0,5 & 0,47 & 0,45 & 0,3 & 0,43 & 0,47 & 0,38 & 0,43 & 0,4 & 0,44 & 0,49 & 0,63 & 1 & & & & \\
\hline $\mathrm{DE} 3$ & 0,41 & 0,36 & 0,49 & 0,28 & 0,49 & 0,41 & 0,43 & 0,26 & 0,38 & 0,36 & 0,27 & 0,37 & 0,37 & 0,36 & 0,34 & 0,45 & 0,58 & 1 & & & \\
\hline $\mathrm{DE} 4$ & 0,36 & 0,3 & 0,41 & 0,18 & 0,35 & 0,32 & 0,27 & 0,08 & 0,27 & 0,21 & 0,17 & 0,21 & 0,18 & 0,22 & 0,27 & 0,31 & 0,39 & 0,5 & 1 & & \\
\hline DE5 & $-0,01$ & -0 & 0,04 & 0,02 & 0,06 & 0,06 & $-0,05$ & $-0,06$ & 0,03 & 0,02 & 0,09 & 0,01 & $-0,01$ & $-0,1$ & 0,03 & 0,13 & 0,13 & 0,06 & 0,1 & 1 & \\
\hline $\mathrm{DE} 6$ & 0,03 & 0,04 & $-0,03$ & 0,02 & 0,03 & 0,02 & $-0,08$ & 0,01 & $-0,01$ & $-0,01$ & $-0,04$ & $-0,1$ & $-0,08$ & $-0,12$ & $-0,01$ & 0,07 & 0,09 & & & 0,62 & 1 \\
\hline
\end{tabular}

Apesar das variáveis não estarem totalmente bem correlacionadas entre si, isto é, algumas variáveis do grupo dirigentes possuem correlação em módulo menor que 0,3 , o teste de KMO apresentado na Tabela 7 demonstra valores maiores que 0,8 (acima do mínimo recomendado de 0,5) nas dimensões social, ambiental e econômica,

Tabela 7 - Teste de KMO das perguntas para os dirigentes e associados

\begin{tabular}{l|r|r|r}
\hline \multicolumn{1}{c|}{ Dirigentes } & Social & Ambiental & Econômica \\
\hline Kaiser-Meyer-Olkin Measure of Sampling Adequacy & 0,879 & 0,869 & 0,818 \\
\hline Bartlett's Test of Sphericity & & & \\
Approx. Chi-Square & 725,590 & 922,495 & 465,524 \\
Df & 28 & 21 & 15 \\
Sig. & 0 & 0 & 0 \\
\hline \multicolumn{1}{c|}{ Associados } & Social & Ambiental & Econômica \\
\hline Kaiser-Meyer-Olkin Measure of Sampling Adequacy & 0,928 & 0,895 & 0,847 \\
\hline Bartlett's Test of Sphericity & 2477,21 & 2987,50 & 1415,49 \\
Approx. Chi-Square & 28 & 15 & 15 \\
Df & 0 & 0 & 0 \\
Sig. & &
\end{tabular}

O teste de KMO apresentado na Tabela 15 demonstrou, entre os dirigentes e associados, valores significativos e adequados com resultados entre os dirigentes de 0,879 na dimensão social, 0,869 na dimensão ambiental e 0,818 na dimensão econômica, e entre os associados valores de 0,928, 0,895 e de 0,847 nas mesmas dimensões, confirmando a análise dos fatores apropriados para os dados demonstrados.

\section{Considerações Finais}


Este artigo procurou demonstrar - por meio de indicadores, tabelas e gráficos - as percepções dos associados e dirigentes sobre as práticas frequentes na gestão das AABBs que envolvem a sustentabilidade, evidenciando o nível de comprometimento e satisfação dos seus principais stakeholders (associados e dirigentes), bem como as contribuições para o desenvolvimento das comunidades, nas suas respectivas localidades, nos aspectos social, ambiental e econômico. A característica mais evidenciada nas respostas dos questionários deu-se em relação à dimensão ambiental, na qual se pôde perceber, por meio dos percentuais nos fatores "satisfeito e muito satisfeito", que os dirigentes e associados praticam com pouca intensidade ações relacionadas a esse tema. Essa constatação sugere uma reavaliação por parte dos dirigentes e associados das práticas internas e externas dos clubes de forma a integrá-los nas causas socioambientais das comunidades, a fim de que seja possível, inclusive, obter crescimento e melhorias nos resultados das dimensões social e econômica.

Com a realização deste trabalho, foi possível observar que existe um importante viés a ser explorado pelos clubes sociais para que se alcance a sustentabilidade. Embora o tema ainda não esteja na pauta de prioridades, a pesquisa desponta como uma oportunidade para que seus resultados sejam analisados pelos dirigentes das AABBs, com vistas a estabelecer novos padrões de consumo, comportamento interno, externo, e tomada de decisão baseado nos indicadores de satisfação.

O tema é abrangente e propicia a identificação de lacunas que sugerem pesquisas futuras, possibilitando descobertas e análises mais específicas no cenário dos clubes sociais, tais como: a atuação individualizada das AABBs por região, de onde seja possível extrair percepções dos associados e dirigentes dos clubes em cada unidade federativa, visando uma atuação mais centrada nas três dimensões; a influência da cultura popular e dos fatores socioeconômicos na percepção sustentável de associados e dirigentes de forma regionalizada; e a aplicação da dimensão ambiental e seus impactos nas dimensões social e econômica de um clube social são alguns temas vinculados a este trabalho que enunciam novos estudos.

Pesquisas nessa dimensão (ambiental, social e econômica) devem ser intensificadas em segmentos diversos pela comunidade científica, a fim de que possam contribuir para o desenvolvimento sustentável de comunidades, clubes e associações identificando lideranças, pessoas ou instituições, que gozam de credibilidade e que tenham gestores que possam tomar decisões baseadas nas percepções dos seus clientes gerando motivação nos participantes com seriedade, respeito e determinação.

\section{REFERÊNCIAS}

ALMEIDA, F. O bom negócio da sustentabilidade Rio de Janeiro, 2001.

ALMEIDA, F. J. R. Ética e desempenho social das organizações: um modelo teórico de análise dos fatores culturais e contextuais RAC, 11 (3) 105-125 Rio de Janeiro, 2007.

ATKISSON, A.; HATCHER, L. The compass index of sustainability: prototype for a comprehensive sustainability information system Journal of Environmental Assessment Policy and Management, 3,(4) 509-532, 2001.

BARBETTA, P. A. Estatística aplicada às ciências sociais 6 (1) Florianópolis, 2006.

BARDDAL, R. Viabilidade de projetos e a inserção das dimensões de sustentabilidade: Uma aplicação em projetos turísticos, Mestrado em Administração - UNIVALI, 2008. 
BARDDAL, R.; ALBERTON, A.; CAMPOS, L. M. S. As dimensões e métodos de mensuração da sustentabilidade e o turismo: uma discussão teórica RGSA, 4 (2) 138-155. 2010.

BARROS, J. D. S.; SILVA, M. F. P. Aspectos teóricos da sustentabilidade e seus indicadores. Revista eletrônica Polêmica, 11 (1) 104-112, 2012.

BRAMANTE, A. C. Estudo de caso para a formulação de uma política setorial de lazer: avaliação contextual do Distrito Federal. Revista da faculdade de Educação Física da UNICAMP, 1 (2): 121-145., 1999.

BRASIL. Decreto-Lei $\mathbf{n}^{\circ}$ 9.795. Qualificação como organização da sociedade civil de interesse público. Disponível em: <http://www.planalto.gov.br/ccivil_03/leis/L9790.htm>. Acesso em: 15 de jul.2015.

BREIER, G. P; JUNG, C. F.; TEN CATEN, C. S. Análise e síntese de modelos para avaliação da sustentabilidade de empresas Belo Horizonte - MG, 2015.

CAMARGO, L. A. R.; SILVA, M. R. Os clubes sociais e recreativos e o processo civilizatório brasileiro: Uma relação de hábitos e costumes. In: XI Simpósio Internacional Processo Civilizador (2008), Buenos Aires. Anais... Universidade de Buenos Aires, p. 68-75, 2008.

CAMPOS, C. A.; RIBEIRO, F. L. Aplicação da ferramenta Dashboard of Sustainability no processo de avaliação do desenvolvimento sustentável na agricultura familiar, 2007.

CAPI, A. H. C.; MARCELLINO, N. C. Clubes social-recreativos: Lazer, associativismo e atuação profissional. Revista Cesumar, 20 (3) 465-475, 2009.

CARVALHO, B. L. P. Associativismo, lazer e esporte nos clubes sociais de Campinas. (Mestrado em Educação Física) - Faculdade de Educação Física, Universidade de Campinas, 2009.

CHIAVENATO, I. Os novos paradigmas: Como as mudanças estão mexendo com as empresas 4 (1) São Paulo, 2003.

CONFEDERAÇÃO BRASILEIRA DE CLUBES SOCIAIS CBC. Disponível em: http://www.cbcclubes.com.br. Acesso em 18 de novembro 2015.

Collins, J.; Hussey, R. Pesquisa em administração - Um guia prático para alunos de graduação e pós-graduação 2 Porto Alegre.

DEPONTIL, C. M.; ALMEIDA, J. Indicadores para avaliação da sustentabilidade em contextos de desenvolvimento rural local, 2002.

DIAS, R.; CASSAR, M.; ZAVAGLIA, T. Introdução à administração da competitividade à sustentabilidade. Campinas, 2013.

DOW JONES. Dow Jones sustainability index. Disponível em: <https://www.sustainabilityindexex.com>. Acesso em: 17 de maio 2015.

FEDERAÇÃO NACIONAL DAS AABBs FENABB. Estatuto Social. Disponível em: $<$ https://www.fenabb.org.br> Acesso em: 10 de jun. 2014.

FREITAS, H.; OLIVEIRA, M.; SACCOL, A. Z; MOSCAROLA, J. O método de pesquisa survey. Revista de Administração 35 (3) 05-112 São Paulo, 2000.

GLOBAL REPORTING INITIATIVE GRI. Diretrizes para Relatórios em Sustentabilidade G4. Disponível em: <www.globalreporting.org> Acesso em: 17 de maio 2014.

HAIR, J.F. Jr.; BABIN, B.; MONEY, A. H.; SAMOUEL, P. Fundamentos de modelos de pesquisa em administração. Porto Alegre, 2005.

HARDI, P.; ZDAN, T. J. Assessing sustainable development: principles in practice International Institute for sustainable development. 1997.

LIBARDI, R. Os clubes do Brasil. Disponível em: <https://www.rlsolucoes.com.br> Acesso em: 28 de abr. 2014. 
LOUETTE, A. Compêndio de indicadores de sustentabilidade de nações: uma contribuição ao diálogo da sustentabilidade. Antakarana: Cultura Arte Ciência / Willis H. House, 2009.

MALHEIROS, T. F.; PHLIPPI JR, A.; COUTINHO, S., M, V. Agenda 21 nacional e indicadores de desenvolvimento sustentável. Revista Saúde e Sociedade, 17 (1) 7-20, 2008.

MARTINS, M. F.; CÂNDIDO, G. A. Modelo de avaliação do nível de sustentabilidade urbana: proposta para as cidades brasileiras. Revista Brasileira de Gestão Urbana, 2015.

MEZZADRI, F.M. A estrutura esportiva no Estado do Paraná: da formação dos clubes esportivos às atuais políticas governamentais Tese (Doutorado em Educação Física da Faculdade de Educação Física) - Universidade Estadual de Campinas, Campinas, 2000.

NASCIMENTO, E.; TELLO, R.; OLIVEIRA, C. Responsible competitiveness: reshaping gobal markets through responsible business practices accountability e Fundação Dom Cabral, SP, 2005.

NETO, W. J. S. Síntese que organiza o olhar: uma proposta para construção e representação de indicadores de desenvolvimento sustentável e sua aplicação para os municípios fluminenses. Dissertação (Mestrado em Estudos Populacionais e Pesquisas Sociais) - Escola Nacional de Ciências Estatísticas, Rio de janeiro, 2006.

PEREIRA, A. L.; BOECHAT, C. B.; TADEU, H. F. B.; SILVA, J. T. M.; CAMPOS, P. M. S. Logística reversa e sustentabilidade. São Paulo, 2012.

PIGA, T.R.; MANSANO, S. R.V. Dimensões políticas da ação ambiental: um estudo de caso de desenvolvimento em questão. Unijuf, n.36, out/dez. 2016 p. 294-319 São Paulo, 2016.

PRESCOTT-ALLEN, R. The wellbeing of nations: a country-by-country index of quality of life and the environment. IUCN - The World Conservation Union International Institute for Environment and Development Food and Agriculture Organization of the United Nations Map Maker Ltd, Washington, 2001.

RANGANATHAN, J. Sustainability rulers: measuring corporate environmental \& social performance. World Resources Institute, Washington, 1998.

RECH, S. História da FENABB. Brasília, 2000.

RIEDE, S. Fatores críticos de sucesso na gestão das AABBs - Associações Atléticas Banco do Brasil. 2002. Dissertação (Mestrado em administração) - Escola Brasileira de Administração Pública, Fundação Getúlio Vargas, Brasília, 2002.

SILVA, C. L.; WIENS, S. Indicadores: conceitos e aplicações. In: SOUZA-LIMA, J. E (Org.). Políticas públicas e indicadores para o desenvolvimento sustentável. São Paulo, 2010.

VALLE, C. E. Qualidade ambiental: ISSO 1400012 (1), São Paulo, 2012.

VAN BELLEN, H. M. V. Indicadores de sustentabilidade: uma análise comparativa. 2 ed. Rio de Janeiro, 2006.

VELEVA, V. \& ELLENBECKER, M. Addressing shortcomings in existing frameworks. University of Massachusetts Lowell, USA, 2000.

ZEITHAML, V. A.; BITNER, M. J. Marketing de serviços: a empresa com foco no cliente. Porto Alegre: Bookman, 2003. 